\title{
Fatty Acids and Their Metal Salts: A Review of Their Infrared Spectra in Light of Their Presence in Cultural Heritage
}

\author{
Anna Filopoulou (D), Sophia Vlachou (D) and Stamatis C. Boyatzis *(D) \\ Department of Conservation of Antiquities and Works of Art, University of West Attica, 12243 Egaleo, Greece; \\ annafilopoulou.s@gmail.com (A.F.); ca15011@uniwa.gr (S.V.) \\ * Correspondence: sboyatzis@uniwa.gr; Tel.: +30-21-0538-5464
}

Citation: Filopoulou, A.; Vlachou, S.; Boyatzis, S.C. Fatty Acids and Their Metal Salts: A Review of Their Infrared Spectra in Light of Their Presence in Cultural Heritage. Molecules 2021, 26, 6005. https:// doi.org/10.3390/molecules26196005

Academic Editors: Maria Luisa Astolfi, Maria Pia Sammartino and Emanuele Dell'Aglio

Received: 8 September 2021

Accepted: 28 September 2021

Published: 3 October 2021

Publisher's Note: MDPI stays neutral with regard to jurisdictional claims in published maps and institutional affiliations.

Copyright: (c) 2021 by the authors. Licensee MDPI, Basel, Switzerland. This article is an open access article distributed under the terms and conditions of the Creative Commons Attribution (CC BY) license (https:/ / creativecommons.org/licenses/by/ $4.0 /)$.

\begin{abstract}
In a cultural heritage context, fatty acids are usually found as breakdown products of lipidcontaining organic remains in archaeological findings, binders in aged oil paintings, and additives in modern art-related materials. They may further interact with the ionic environment transforming into metal soaps, a process that has been recognized as a threat in aged paintings but has received less attention in archaeological objects. The investigation of the above related categories of materials with infrared spectroscopy can provide an overall picture of the organic components' identity and demonstrate their condition and prehistory. The capability of investigating and distinguishing fatty acids and their metal soaps through their rich infrared features, such as the acidic carbonyl, the carboxylate shifts, the variable splits of alkyl chain stretching, bending, twisting, wagging, and rocking vibrations, as well as the hydroxyl peak envelopes and acid dimer bands, allows for their direct detailed characterization. This paper reviews the infrared spectra of selected saturated fatty monoacids and diacids, and their corresponding sodium, calcium, and zinc salts and, supported by newly recorded data, highlights the significance of their spectroscopic features.
\end{abstract}

Keywords: fatty acids; metal soaps; oil binder; archaeological organic remains; infrared spectroscopy

\section{Introduction}

Lipids (glycerol triesters), existing as organic residues in archaeological findings (such as pottery and metal vessels) or as binders in oil paintings, are prone to hydrolytic damage producing free fatty acids (FA) [1-4]. Furthermore, FA in aged oil paintings may further react with abundant pigment metal ions in their molecular vicinity to form fatty acid metal salts (FAMS, metal soaps) [5-7]. Similar reactions may occur with calcium and other metal ions in archaeological samples, although they have been investigated in relatively fewer circumstances [8-10].

The analytical investigation of organic archaeological residues has received attention due to the resilience of organic molecules, such as lipids and their breakdown products, which helps researchers access information on dietary habits, rituals, and other practices developed by cultures of the past [11-15]. For instance, extended research has been done in ancient unglazed pottery since they offer a convenient protective medium, though allowing for the intrusion of organic compounds, preserves said compounds from environmental degradation for millennia [16-38]. Relatively fewer cases have been reported in wooden containers such as coffins [39] or metal alloys such as copper [9,40]. Most of the above cases have been studied through gas chromatography combined either with mass spectrometry (GC-MS) [18,20,28,33,34,38,41-43] or isotope ratio mass spectrometry (GC-IRMS) [30,36-38,41]. This technique allows for the accurate quantification of analytes. For instance, the oil content was analyzed in ancient amphorae found in the Late Bronze Age shipwreck of Uluburun [26] and the site of Amarna (Egypt) [44], or shipwrecks dating from the First Punic War [45]. In addition, the profiling of the adsorbed oil gradient within the clay fabric of potsherds has been investigated [44]. 
The acquisition of infrared spectra significantly assists analytical efforts, such as the ones mentioned above. Although detailed infrared analysis, such as the chemical mapping of paint cross-sections has been successfully conducted [46-48], the technique has generally been restricted to simple 'screening' or 'fingerprinting' in organic residue analysis. Nevertheless, its value has been recognized for guiding further analytical efforts [31,49]. Infrared spectroscopic analysis of lipid-containing samples is a fast technique that generally demands minimal sample workup, which based on their molecular bonding [24,50-52], provides rich information on their chemical components [50,53-55], such as glycerol esters, fatty acids, and metal salts. However, interpretation of complex samples can be tedious and problematic since frequent band overlaps impose difficulties for a secure assignment [56-62]. Thus, a necessity emerges for the accurate identification of fatty components in samples characterizing their existing condition through close examination of their infrared spectra.

In addition, advanced technological capabilities have led to the development of reflection-based techniques in combination with microscopy $[7,46,48,63-68]$, which vastly expanded the depth of information offered by the method.

In the field of art, infrared spectroscopy has played a significant role in identifying and studying the binding media in oil paintings $[7,69,70]$, and possibly more importantly, the severe deterioration caused by the formation of metal soaps $[7,47,69,71-79]$. In archaeology, infrared spectroscopy has also played a decisive role in analyzing organic archaeological residues $[9,11,32,39,40,79]$. Identifying fatty substances through their infrared spectra can elucidate chemical transformations such as the mineralization of acidic organic components in aged samples. Notably, organic molecular markers that connect the current condition of the materials with their original one can assess the prehistory of cultural heritage objects and their possible uses in antiquity $[9,11,25,32,39,66,80,81]$.

This paper reviews the infrared spectra of selected fatty monoacids, diacids, and their sodium, calcium, and zinc salts, and points out their detailed features for detecting these compounds directly in their samples and further assessing their structural condition. The rich information gained through the close inspection of spectroscopic features can help researchers benefit in their investigations to a level beyond typical infrared screening.

\section{Results and Discussion}

\subsection{Molecular Structure Phenomena in Fatty Acids}

The intermolecular attraction of acidic carbonyls due to hydrogen bonding induces a dimerization phenomenon where FA associate in a handshake mode forming headto-head molecular pairs (or 'dimers') [82-86]. This was first shown experimentally by Pauling, followed by normal mode vibrational analysis $[87,88]$. In combination with hydrophobic alkyl chain associations, the above results in the bilayer coordination of fatty acid molecules described in Figure 1a [89-91]. Extensively studied through infrared spectroscopy, hydrogen bonding has been recognized and studied in alcohols and carboxylic acids since the 1930s [86,92-96]. As a concept, it gained profound attention in the second half of the previous century [87,88,95,97-101], while advanced computational capabilities during the last two decades have further led to elucidating intermolecular phenomena [102,103].

Carboxylic acids carry a hydrogen bond donor (the OH group) and a hydrogen bond acceptor $(\mathrm{C}=\mathrm{O})$ within the same unit and are, therefore, ideal molecules for studying the phenomenon. First, as a profound manifestation of the hydrogen bonding attraction, the hydroxyl stretch is considerably downshifted, compared to their 'free' state, and characteristically broadened [93-95,101]. Secondly, the dimerization phenomenon induces additional dimer infrared bands due to the impeded stretching of associated hydroxyls and carbonyls and restricted bending of the $\mathrm{C}-\mathrm{O}-\mathrm{H}$ group (see below). Moreover, intermolecular associations between long alkyl chains of FA induce crystal packing (Figure 1), affecting their melting points $[104,105]$ and infrared spectra. 


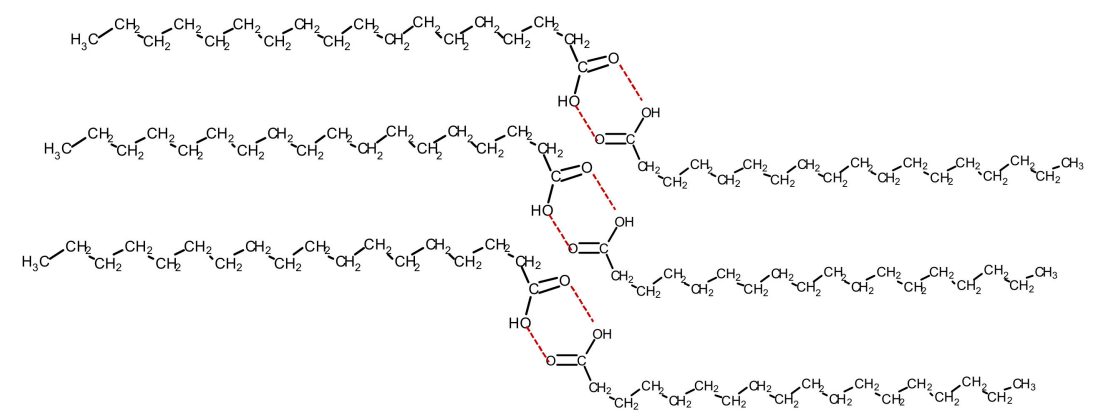

(a)

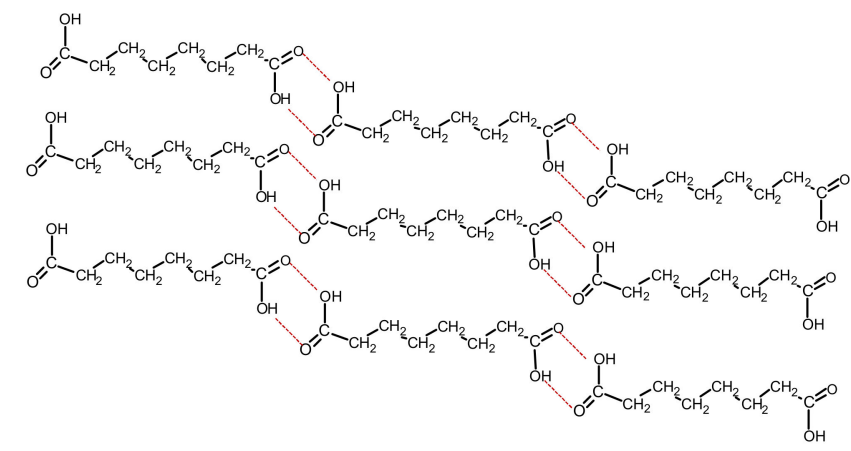

(b)

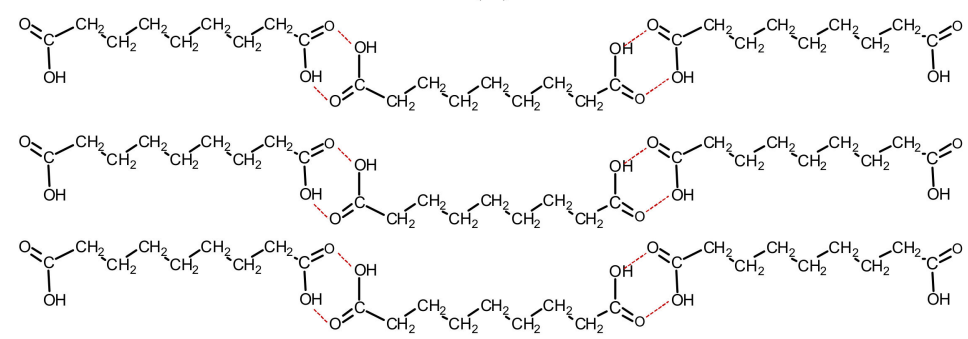

(c)

Figure 1. Molecular conformations of fatty acids. (a) Type B structure of stearic acid (adapted from [94]); (b) octanedioic acid (C8di) and (c) nonanedioic acid (C9di) (adapted from [96]).

\subsection{Infrared Spectra of Saturated Monoacids and Their Metal Salts}

\subsubsection{Monoacids}

The infrared spectra of saturated fatty acids (sFA) have been studied and their features have been previously reported [106-111]. In particular, studies for C8:0-C18:0 [112-116] may provide powerful identification tools. The published information, supported by newly recorded spectra, is presented and discussed below.

In sFA, the zig-zag hydrocarbon chains assume an overall linear direction, which generally allows for close chain approaching in the bulk phases, and finally, for diverse polymorphic structures, which subtly differ for odd- and even-numbered acids $[108,109,115,116]$. Fatty acids with chains shorter than that of C9:0 are liquid at room temperature, while C10:0, with a melting point of $31.3^{\circ} \mathrm{C}$, is marginally crystallizable [117]. The latter, along with the higher FA, show pronounced structural infrared features indicative of the crystalline state. Furthermore, even-numbered fatty acids, such as stearic (C18:0), crystallize in temperature-dependent polymorphs $\mathrm{A}$ (triclinic) and $\mathrm{B}, \mathrm{C}$, and $\mathrm{E}$ (monoclinic with orthorhombic sub-cells) $[89,108,118]$. Structure $C$ is observed at temperatures higher than $35^{\circ} \mathrm{C}$. At room temperature, the metastable monoclinic structure $\mathrm{E}$ transforms to the dominating orthorhombic structure B (shown in Figure 1a), where head-to-head acid pairs in trans-planar (or fully extended) chain geometry are formed $[89,103,118,119]$. This allows the alignment and packing of hydrocarbon chains. 
To better study FA infrared spectra, the spectra can be divided into seven regions, each generally having a particular vibrational character. Maxima and assignments are shown in Table 1.

Table 1. Main infrared peaks and assignments of saturated fatty carboxylic monoacids and diacids.

\begin{tabular}{|c|c|c|c|c|}
\hline \multicolumn{3}{|c|}{ Peak Maxima, Wavenumbers $\left(\mathrm{cm}^{-1}\right)^{1}$} & \multirow[b]{2}{*}{ Assignment } & \multirow[b]{2}{*}{ Notes } \\
\hline Monoacids & $\begin{array}{l}\text { Octanedioic } \\
\text { (Suberic) Acid }\end{array}$ & $\begin{array}{l}\text { Nonanedioic } \\
\text { (Azelaic) Acid }\end{array}$ & & \\
\hline $3600-2800 \mathrm{br}$ & 3037 & 3045 & $v \mathrm{OH}$ & $\begin{array}{l}\text { Typically, very broad with } \\
\text { vague maximum. }\end{array}$ \\
\hline $2960-2956 \mathrm{~m}-\mathrm{w}$ & n.a. & n.a. & $v_{\text {as }} \mathrm{CH}_{3}$ & $\begin{array}{l}\text { Variable, according to the number } \\
\text { of carbons. }\end{array}$ \\
\hline $2934-2919 \mathrm{~s}$ & $\begin{array}{l}\text { 2991, 2951, 2941, } \\
2911\end{array}$ & 2977, 2937, 2915 & $v_{\mathrm{as}} \mathrm{CH}_{2}$ & $\begin{array}{l}\text { Variable, according to the number of } \\
\text { carbons; higher-frequency maxima } \\
\text { correspond to a lower distance from } \\
\text { the COOH group. }\end{array}$ \\
\hline $2875-2872 \mathrm{w}, \mathrm{s}$ & n.a. & n.a. & $v_{\mathrm{S}} \mathrm{CH}_{3}$ & $\begin{array}{l}\text { Variable, according to the number } \\
\text { of carbons. }\end{array}$ \\
\hline $2851 \mathrm{~m}-\mathrm{s}$ & 2872,2855 & $2875,2858,2847$ & $v_{\mathrm{s}} \mathrm{CH}_{2}$ & $\begin{array}{l}\text { Variable, according to the number } \\
\text { of carbons. }\end{array}$ \\
\hline $2670,2565 \mathrm{br}$ & $\begin{array}{l}2759,2676,2599, \\
2534\end{array}$ & $\begin{array}{l}2774,2698,2621, \\
2553\end{array}$ & $\begin{array}{c}v \mathrm{O}-\mathrm{H} \bullet \bullet \bullet \mathrm{O}=\mathrm{C} \\
\text { (dimer stretching } \\
\text { band) }\end{array}$ & $\begin{array}{l}\text { Structured with weak shoulders; more } \\
\text { extended in diacids. }\end{array}$ \\
\hline 1703 vs & 1695 & 1694 & $v \mathrm{C}=\mathrm{O}$, acidic & \\
\hline $1472,1464,1411 \mathrm{~m}$ & 1470,1410 & 1471,1411 & $\delta \mathrm{CH}_{2}$ scissoring & $\begin{array}{l}\text { Split into three components (two in } \\
\text { diacids); the } 1472 \text { and } 1464 \mathrm{~cm}^{-1} \\
\text { components are better resolved for } \\
\text { monoacids C16-C24. }\end{array}$ \\
\hline $1457-1450 \mathrm{w}$ & n.a. & n.a. & $\delta_{\mathrm{as}} \mathrm{CH}_{3}$ & $\begin{array}{l}\text { Contribution is lower for higher } \\
\text { carbon-number chains. }\end{array}$ \\
\hline $1431 \mathrm{~m}-\mathrm{w}$ & 1426 & 1436 & $\delta_{\mathrm{ip}} \mathrm{COH}$ & $\begin{array}{c}\text { Relatively broad; often missed } \\
\text { due to overlaps. }\end{array}$ \\
\hline $1372 \mathrm{~m}-\mathrm{w}$ & & & $\begin{array}{l}\delta_{\mathrm{s}} \mathrm{CH}_{3} \text { ('umbrella' } \\
\text { vibration) }\end{array}$ & \\
\hline $1356-1347 \mathrm{~m}-\mathrm{w}$ & 1334 & 1360,1346 & $\tau \mathrm{CH} 2$ & $\begin{array}{l}\text { Splitting in progressions for acids in } \\
\text { their crystalline state (in room } \\
\text { temperature, higher than C10). }\end{array}$ \\
\hline $1318-1185 \mathrm{~m}-\mathrm{w}$ & 1360,1346 & $\begin{array}{l}1317,1282,1268 \\
1254,1208,1196\end{array}$ & $w \mathrm{CH} 2$ & $\begin{array}{l}\text { Splitting in extended progressions for } \\
\text { acids in their crystalline state (in room } \\
\text { temperature, higher than } \mathrm{C} 10 \text { ). }\end{array}$ \\
\hline 1112-1075 m-w & n.o. & 1105,1098 & $v \mathrm{C}-\mathrm{OH}$ & $\begin{array}{l}\text { Up-shifted for longer hydrocarbon } \\
\text { chains. Weak, or not observed } \\
\text { for diacids. }\end{array}$ \\
\hline $943-935 \mathrm{~m}, \mathrm{br}$ & 932 & 920 & $\begin{array}{l}\delta_{\mathrm{oop}} \mathrm{C}-\mathrm{O}-\mathrm{H} \bullet \bullet \bullet \mathrm{O}=\mathrm{C} \\
\text { (bending dimer } \\
\text { band) }\end{array}$ & \\
\hline $795-741,725-710 \mathrm{w}$ & 796,725 & 776,726 & $\rho \mathrm{CH} 2$ & $\begin{array}{l}\text { Stronger in long hydrocarbon chains; } \\
\text { the } 725 \mathrm{~cm}^{-1} \text { peak is doubly split in } \\
\text { crystalline monoacids. }\end{array}$ \\
\hline 690 & 683 & 681 & $\delta_{\text {oop }} \mathrm{C}-\mathrm{O}-\mathrm{H}$ & \\
\hline
\end{tabular}

\footnotetext{
${ }^{1}$ in bold: the stronger peaks in the case of multiplets. $v$ : stretching vibration; vs. symmetric stretching; $v_{a s}$ antisymmetric stretching; $\delta$ : bending vibration; $\delta_{s}$ symmetric bending; $\delta_{a s}$ antisymmetric bending; $\delta_{\text {ip }}$ : in-plane bending; $\delta_{\text {oop }}$ : out-of-plane bending; $\rho$ : rocking vibration; $\tau$ : twisting vibration; $w$ : wagging vibration.
}

\section{The Acidic Hydroxyl Stretching Region}

The hydroxyl group is involved in the intense hydrogen bonding between molecules of the same type, which controls the structural conformations in the unit cell (Figure 1a). The $\mathrm{O}-\mathrm{H}$ stretching region contains a typically broad, intense band, indicative of the acidic $\mathrm{OH}$ 
hydrogen bonding at $3600-2800 \mathrm{~cm}^{-1}$ with a vague maximum of around $3050-3000 \mathrm{~cm}^{-1}$ (Figure 2a).

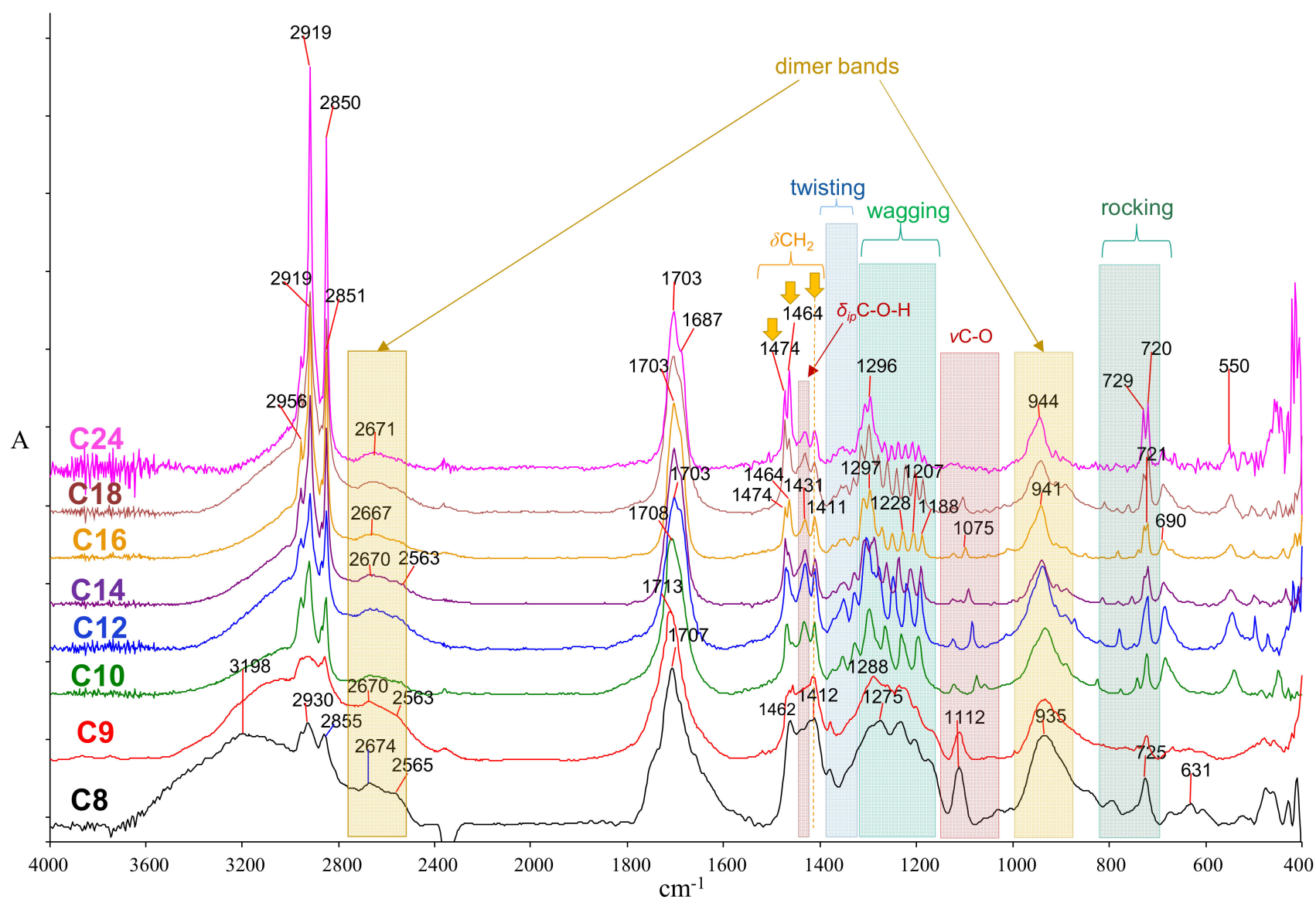

(a)

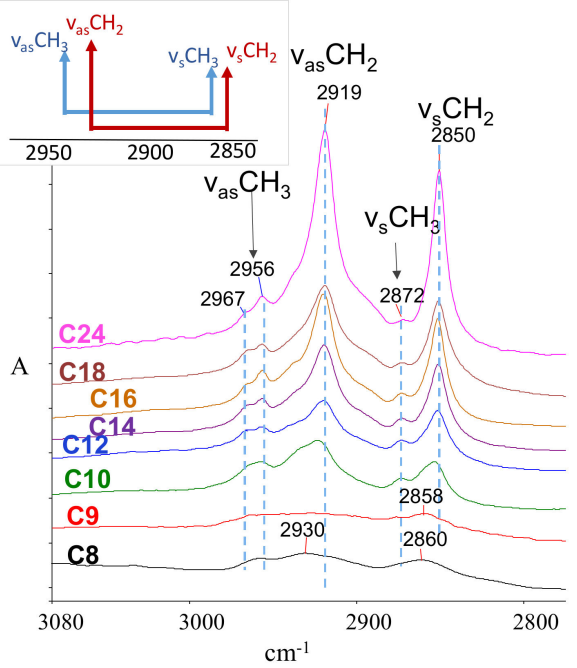

(b)

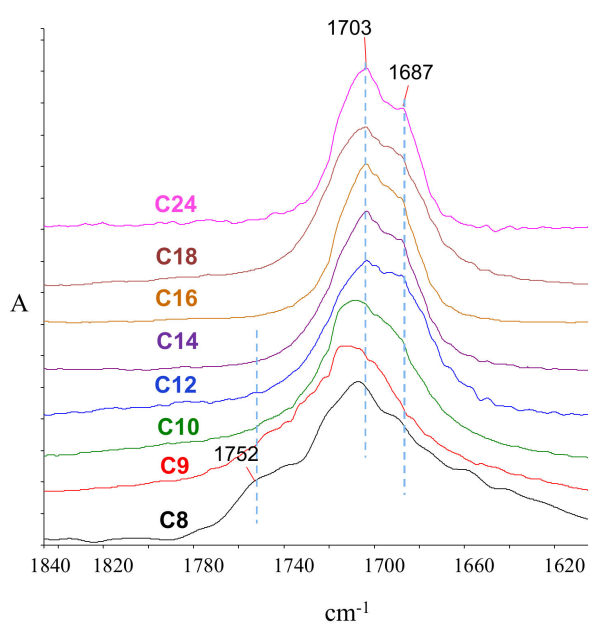

(c)

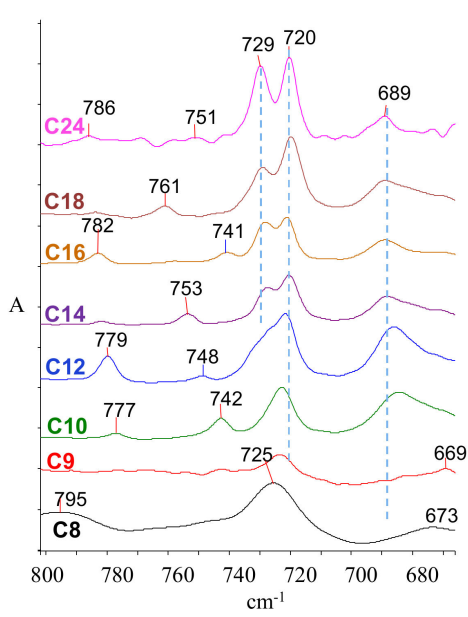

(d)

Figure 2. Infrared spectra of fatty acids. (a) Full spectra with shaded areas highlighting characteristic features; (b) C-H stretching; (c) carbonyl stretching; and (d) rocking vibrations. In all spectra: (i) C8, octanoic; (ii) C9, nonanoic; (iii) C10, decanoic; (iv) C12, dodecanoic; (v) C14, tetradecanoic; (vi) C16, hexadecanoic; (vii) C18, octadecanoic; (viii) C24, tetracosanoic. The negative peak at $\sim 2380 \mathrm{~cm}^{-1}$ for $\mathrm{C} 8$ corresponds to carbon dioxide as a result of improper background subtraction. 
An additional broad band at $2750-2500 \mathrm{~cm}^{-1}$ is assigned to hydroxyl-carbonyl interactions due to acid dimers [120]. Weak maxima are also observed in this region at $\sim 2670$ and $2560 \mathrm{~cm}^{-1}$, often labeled as 'satellite bands,' and are somewhat unclear as they have been assigned to contributions from combination/summation of $\delta \mathrm{OH}$ and $v \mathrm{C}-\mathrm{O}$, Fermi resonance, as well as ionic resonance structures [57,121-123]. Nevertheless, they may work as supporting evidence for detecting FAs through infrared spectra of complex mixtures [57].

\section{The C-H Stretching Region}

The structural similarities between hydrocarbon chains in sFA and n-alkanes were recognized early and associated with their infrared spectra $[107,109]$, although crucial differences were also pointed out [124]. The $\mathrm{C}-\mathrm{H}$ stretch region contains the methyl $\left(\mathrm{CH}_{3}\right)$ and methylene $\left(\mathrm{CH}_{2}\right)$ vibrations, each of these sub-categorized into antisymmetric (asym-) and symmetric (sym-) vibrations $[58,59,108,109,125]$, the former always observed at higher wavenumbers than the latter (Figure 2b). The maxima depend on the methyl or methylene group proximities to the carbonyl group (the closer to the carboxyl group, the higher the frequency) and the hydrocarbon chain length. Interestingly, the $v_{\mathrm{as}} \mathrm{CH}_{2}$ maxima for acids $\mathrm{C} 3$ and C4, with only $\alpha$ - and $\beta$ - methylene groups (spectra not shown here), appear as high as 2990 and $2973 \mathrm{~cm}^{-1}$, respectively $[108,126]$. Additional $\mathrm{CH}_{2}$ groups that build longer chains contribute to the methylene stretching band with a maxima around $2932 \mathrm{~cm}^{-1}$ (as shown in the deconvolution analysis in Figure S3a-c). Further addition of $\mathrm{CH}_{2}$ groups contributes to the sub-band at 2921-2919 $\mathrm{cm}^{-1}$ (Figure S3b,c). For C18:0, the $2919 \mathrm{~cm}^{-1}$ peak is the main contributor to the antisymmetric band.

A trend for $v_{\mathrm{as}} \mathrm{CH}_{3}, v_{\mathrm{as}} \mathrm{CH}_{2}, v_{\mathrm{s}} \mathrm{CH}_{3}$, and $v_{\mathrm{s}} \mathrm{CH}_{2}$ maxima as a function of the hydrocarbon chain length can be seen in Figure 3. The maxima decrease from short to mid-size (C12) chains, beyond which no significant change is marked (within the spectra acquisition resolution: $4 \mathrm{~cm}^{-1}$ ). Moreover, the intensity ratios of methylene over methyl peaks are related to the number of $\mathrm{CH}_{2}$ groups in the chain, thus reflecting the hydrocarbon chain length.

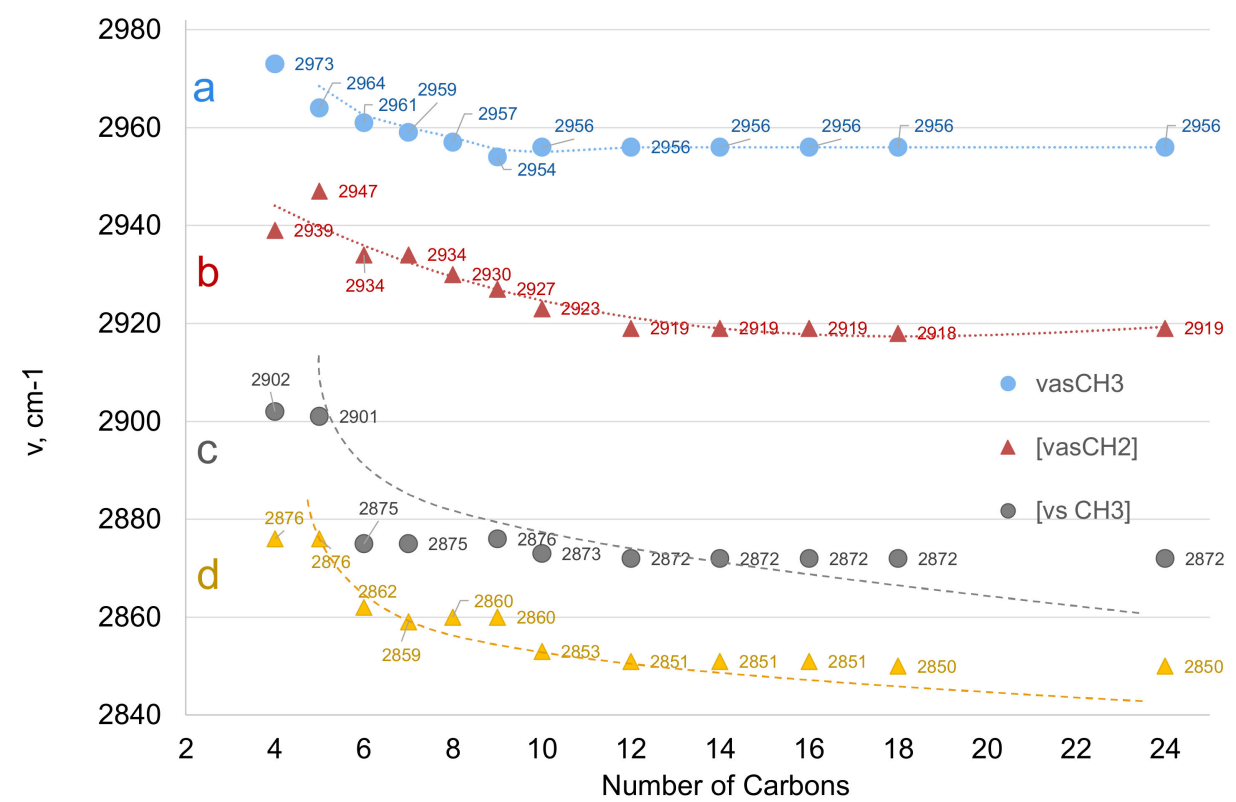

Figure 3. Graph illustrating the trends for (a) $v_{a s} \mathrm{CH}_{3}$, (b) $v_{a s} \mathrm{CH}_{2}$, (c) $v_{s} \mathrm{CH}_{3}$, and (d) $v_{s} \mathrm{CH}_{2}$ peak maxima with respect to the total number of carbons in sFA. Lower-chain acids, not discussed in the main text, are included to further emphasize the trend.

\section{The Acidic Carbonyl Stretching Region}

The carbonyl group absorption maxima depend on the conformation and packing of the hydrocarbon chains, which are more intense in long chains. The acidic carbonyl stretching vibration maximum $(v \mathrm{C}-\mathrm{O})$ is generally observed around $1710-1700 \mathrm{~cm}^{-1}$ (Figure 2a); 
this maximum is considerably downshifted compared to that of isolated molecules (for instance, in the gas phase) [59]. Since the acidic carbonyl group participates in intermolecular hydrogen bonding with the hydroxyl group of a pairing molecule (Figure 1a), the acidic carbonyl downshifts and relatively broadens (Figure 2c) [58,59]. At room temperature, even-numbered acids from C10 and higher are solid and associate efficiently in their crystal; as a result, hydrogen bonding is stronger and results in moderately down-shifted peaks at $\sim 1700 \mathrm{~cm}^{-1}$. An additional significant feature is the shoulder at $1687 \mathrm{~cm}^{-1}$ observed in C14-C24 (Figure 2c), which can be assigned to a tighter association between dimers.

\section{The $\mathrm{CH}_{2}$ and $\mathrm{CH}_{3}$ Bending Region}

The methylene vibration is typically observed at $1465-1430 \mathrm{~cm}^{-1}$ for all sFA due to the symmetric in-plane bending (or 'scissoring') mode, as shown in Figure 2. A sharp, medium-strong peak around $1470 \mathrm{~cm}^{-1}$ is observed. For longer alkyl chain acids, the band is resolved in two sub-bands $\left(\sim 1473\right.$ and $\left.1464 \mathrm{~cm}^{-1}\right)$ with a contribution of the $\alpha-\mathrm{CH}_{2}$ group at $\sim 1411 \mathrm{~cm}^{-1}$. On the other hand, the $\mathrm{CH}_{3}$ symmetric bend (the 'umbrella' vibration) appears at around $1370-1350 \mathrm{~cm}^{-1}$, while the antisymmetric appears at $1473 \mathrm{~cm}^{-1}[56,58,59,127,128]$; the relative intensity of these bands generally diminishes with increasing hydrocarbon chain length. Figure S1 zooms in the $1570-1000 \mathrm{~cm}^{-1}$ region, showing bands more clearly for the crystallizable FAs.

\section{The $\mathrm{CH}_{2}$ Twisting and Wagging Region}

This region is characteristic of crystallizable compounds and materials containing long saturated hydrocarbon chains; as a typical feature, band splitting in the form of band progressions appears [59] (shown in Figure 2a and, in more detail, in Figure S1). Early systematic studies that started in the 1950s, based on the coupled oscillator model of the zigzag-shaped hydrocarbon chain $[107,124,129,130]$, offered a better understanding of this phenomenon. In the crystalline state, the twisting vibration of sFA is split throughout 1368-1329 $\mathrm{cm}^{-1}$ which better resolves upon chain increase; double-split $\mathrm{CH}_{2}$ twisting peaks are observed in C14:0-C18:0, while four-split are observed in C24:0.

A similar phenomenon is even more pronounced for the methylene wagging vibrations, where extensive splitting in the form of progressions at $1320-1160 \mathrm{~cm}^{-1}$ are observed [107-110,131]. The multiplicity of progressions (which can be termed as $w_{1}, w_{2}$, etc.) increases with increasing hydrocarbon chain length (seen in detail in Supplementary Materials Figure S1), showing a multiplet of bands, the number $w$ of which appears to follow the rule $w=\frac{n}{2}-1$, where $n$ is the total number of carbons in a fatty acid. Moreover, the distancing between consecutive $w$ bands diminishes with increasing hydrocarbon chain, approx. 34 (for C10), 29 (C12), 24 (C16), 18 (C18), and $13 \mathrm{~cm}^{-1}$ (C24). The progressions may be stronger in well-crystallized samples, for instance, when the crystalline state is slowly formed upon the annealing of a fatty acid melt [108,109,132,133]; this is demonstrated in Figure S3 for stearic acid (C18:0), where a recrystallized C18:0 sample after a heatingannealing cycle is compared with the one that was recorded as purchased. Generally, on a practical level, when these bands are distinguishable, the carbon number of the fatty acid can be estimated.

\section{Hydroxyl C-O Stretch and C-O-H Bending Region}

The carbon-oxygen bond of the acidic hydroxyl stretches $(v \mathrm{C}-\mathrm{O})$ at around $1100 \mathrm{~cm}^{-1}$ and appears as a medium peak (Figure 2a); for liquid fatty acids, the band is relatively broad at $1100-1110 \mathrm{~cm}^{-1}$, while for solid acids, it is split at $1124 \mathrm{~cm}^{-1}$ (weaker) and $1075-1122 \mathrm{~cm}^{-1}$ (stronger). The latter upshifts upon moving from C10:0 to C18:0, while in C24:0 this peak almost disappears (Figure S1).

The C-O-H in-plane bending vibration $\left(\delta_{i p} \mathrm{C}-\mathrm{O}-\mathrm{H}\right)$ is observed as a medium, relatively broad peak at $\sim 1431 \mathrm{~cm}^{-1}$ [59]. Although it is often partly overlapped in unknown, complex samples, its diagnostic value can be significant. Likewise, the out-of-plane bending vibration $\left(\delta_{\text {oop }}\right.$ C-O-H), which typically appears as a weak peak at around $690 \mathrm{~cm}^{-1}$ and 
is also responsible for a medium-strong broad peak at $943-935 \mathrm{~cm}^{-1}$ [56,59] due to dimer formation, is also of diagnostic value (Figure 2a).

\section{The $\mathrm{CH} 2$ Rocking Region}

This band may span in the $780-700 \mathrm{~cm}^{-1}$ range [124]. In-phase $\mathrm{CH}_{2}$ rocking vibration most prominently appears at $725-710 \mathrm{~cm}^{-1}$ (Figure $2 \mathrm{~d}$ ). In the crystalline state (and similarly with hydrocarbons), the band splits into a doublet with $\Delta v 7-10 \mathrm{~cm}^{-1}$, due to the anisotropic coupling of similar vibrations in adjacent $\mathrm{CH}_{2}$ groups [109,134]. As shown in Figure 2d, splitting intensifies for long hydrocarbon chains (C14:0, C16:0, C18:0, and even more for C22:0).

\section{Infrared Maxima and Crystallization}

Most spectral characteristics discussed above depend on the state of fatty acids. Efficient crystal packing results in the downshifting of acidic carbonyl and the formation of $\mathrm{CH}_{2}$ structural features (twisting, wagging progressions, and splitting of bending and rocking vibrations). On the other hand, non-crystallizable sFA, such as C8:0 and C9:0 (melting points $16.5^{\circ} \mathrm{C}$ and $12.4^{\circ} \mathrm{C}$, respectively) show a relatively uniform broad band at $1380-1180 \mathrm{~cm}^{-1}$ with poorly resolved shoulders (Figure 2a); the lack of multiplicities reflects their non-crystalline nature at room temperature. A marginal case is capric acid $\left(\mathrm{C} 10\right.$, melting point $\left.34^{\circ} \mathrm{C}\right)$, where crystallization at room temperature is not always efficient and although the wagging progressions are evident, the carbonyl peak appears upshifted $\left(1708 \mathrm{~cm}^{-1}\right)$, and the rocking vibration is not split (Figure 2a,c).

The rocking band is significant and of diagnostic value regarding the chain length and effectiveness of crystallization. While the twisting and wagging progressions (discussed above) appear for any solid-state FA (i.e., for $\mathrm{C} 10$ and higher), the rocking band splits for chains longer than C14, as shown in Figure 2a,d. Furthermore, effective crystallization may affect the shape of the split band (i.e., even and deeper-split sub-bands in well-crystallized samples). The crystallization effect is shown in Figure $\mathrm{S} 3$ by comparing the $\mathrm{CH}_{2}$ rocking band of C18:0 before and after the annealing-recrystallization cycle. In conditions favoring even more efficient packing (such as freezing in 10K [124]), the rocking vibration is even more split where coupling with the twisting vibration is evident as a progression ranging from 1065 to $720 \mathrm{~cm}^{-1}$.

\subsubsection{Fatty Monoacid Metal Salts}

Fatty acids can be transformed into FAMS in the presence of metals $[135,136]$ and reactive metallic compounds such as oxides, hydroxides, and salts [62,71,137-139]. In paintings, many of these metallic compounds exist in inorganic pigments and have been found to cause soap formation, particularly of zinc and lead, a phenomenon that has received considerable attention from researchers due to the detrimental effects in works of art $[5,77,87,140-142]$. Their presence in archaeological samples and other cultural heritage objects has also been documented [8,9]. In particular, calcium soaps are considered to be common products through FA adsorption to calcium carbonate in the geological environment and ceramics $[27,143,144]$, since their formation is favored due to their very low solubilities in water $\left(K_{\mathrm{sp}}\right.$ of the order of $\left.10^{-17} \mathrm{~mol}^{3} / \mathrm{L}^{3}\right)$. Other metal soaps can also be expected, such as copper, aluminum, cobalt, and iron $[84,139,145]$. This mineralization process, which can be followed by inspecting infrared spectra of samples, may prolong the preservation of the lipid fraction in the burial or other environments due to low solubility. Moreover, the above may lead to a severe underestimation of lipid yields during routine chromatographic analysis involving lipid extraction with organic solvents [27]. In the light of the above, chromatographic analysis methodologies measuring metal soaps as added components in lipid analysis of cultural heritage samples have recently been considered [146]. Finally, contamination by cleaning agents, including the sodium soaps (typically, stearates), may not be excluded. For all the above reasons, identifying FAMS in the sample prior to any chemical processing offers significant help in assessing the overall 
lipid load in a sample and further assessing its prehistory. To this end, the infrared spectra of calcium, zinc, and sodium fatty acid salts are presented, and their characteristic features are pointed out.

The infrared spectra of FAMS have been studied to some extent $[78,87,133,138,147]$. In support of the current discussion, selected sodium (representative of late-historical cleaning agents and modern additives in routinely used materials), calcium (typically expected in interaction products of FA with the calcareous environment) and zinc soaps (a usual case of metal soaps in oil paintings) were prepared in the laboratory (see Materials and Techniques). Their infrared spectra were recorded.

Although soap spectra generally share similar features, diagnostically significant differences can be observed regarding the carboxylate and some of the hydrocarbon chain vibrations. Moreover, in the case of the bivalent ions $\mathrm{Ca}$ and $\mathrm{Zn}$, hydrated salts were produced, as evidenced by the intense, broad, crystalline water peaks (at $\sim 3440$ and $\sim 1626 \mathrm{~cm}^{-1}$ for the calcium salt, and $\sim 3565-3580$ and $1620-1600 \mathrm{~cm}^{-1}$ for the zinc salt). Spectra are shown in Figure 3 (sodium), Figure 4 (calcium), and Figure 5 (zinc), while peaks with their assignments are listed in Table 2.

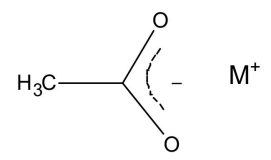

$\mathrm{M}^{+}=\mathrm{Na}^{+}$or $\mathrm{K}^{+}$

(a)

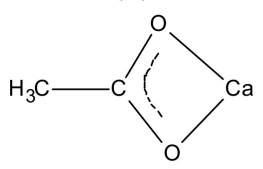

(c)

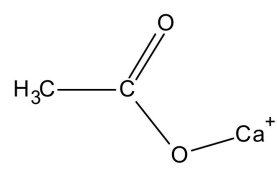

(b)

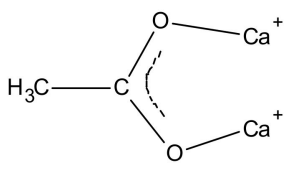

(d)

Figure 4. Chemical structures of metal carboxylates. (a) Ionic form of monovalent metal ions; (b) unidentate coordination; (c) chelating bidentate coordination; and (d) bridging bidentate coordination to calcium ions. Structures adapted from [148,149,152].

The Carboxylate Stretching

The carboxylate bands typically exist in pairs corresponding to the antisymmetric $\left(v_{a s} \mathrm{COO}^{-}\right)$and symmetric $\left(v_{s} \mathrm{COO}^{-}\right)$carboxylate vibrations at $1575-1530$ and $1460-1400 \mathrm{~cm}^{-1}$, respectively.

The coordination geometry plays a significant role in the band maxima [147-149]. Moreover, the separation between the antisymmetric and symmetric band, often called the $\Delta$ ('delta') value, depends on the coordination symmetry; the lower the symmetry, the higher the $\Delta$. More specifically, carboxylates may assume various symmetry levels based on whether they exist in a pure ionic form (or a salt) or metal-coordinated forms such as the unidentate, the chelate bidentate, and the bridging bidentate [148-151] (Figure 4). In the lower-symmetry unidentate complexes (Figure $4 \mathrm{~b}$ ), the antisymmetric maximum is expected to appear close to that of the corresponding carboxylic acid. The more symmetric ionic and chelating bidentate structures (Figure $4 \mathrm{a}, \mathrm{c}$, respectively) appear at roughly similar frequencies, while the bridging bidentate is even lower [149]. The maxima are very sensitive to the metal type (i.e., ion mass, electronegativity, and effective charge [87]) but generally insensitive to alkyl chain length, as shown in Figure S4. 
Table 2. Main infrared peaks and assignments of monoacid and diacid metal salts.

\begin{tabular}{|c|c|c|c|c|}
\hline \multicolumn{3}{|c|}{ Peak Maxima, Wavenumbers $\left(\mathrm{cm}^{-1}\right)$} & \multirow[t]{2}{*}{ Assignment } & \multirow[t]{2}{*}{ Notes } \\
\hline Monoacid Metal Soaps & $\begin{array}{c}\text { Octanedioate } \\
\text { (Suberate) Metal Soaps }\end{array}$ & $\begin{array}{c}\text { Nonanedioate (Azelate) } \\
\text { Metal Soaps }\end{array}$ & & \\
\hline $3600-3300$ & $3590,3521 \mathrm{Zn}$ & $3565,3521 \mathrm{Zn}$ & $v \mathrm{O}-\mathrm{H}$ (cryst. water) & $\begin{array}{l}\text { In Ca and higher } \mathrm{Zn} \text { monoacid } \\
\text { salts. Only in zinc diacid salts. }\end{array}$ \\
\hline 2956 & n.a. & n.a. & $v_{\text {as }} \mathrm{CH}_{3}$ & \\
\hline 2940(sh), 2926-2916 & $\begin{array}{c}2942,2930,2909 \mathrm{Na} \\
2978,2939,2921,2907 \mathrm{Ca} \\
2939,2927,2905 \mathrm{Zn}\end{array}$ & $\begin{array}{c}2943,2936,2921,2907 \\
\mathrm{Na} \\
2976,2947,2921,2915 \mathrm{Ca} \\
2939,2927,291 \mathrm{Zn}\end{array}$ & $v_{\mathrm{as}} \mathrm{CH}_{2}$ & $\begin{array}{c}\text { Downshifted }\left(3-5 \mathrm{~cm}^{-1}\right) \text { in } \\
\text { monoacid salts, for }>\mathrm{C} 16(\mathrm{Ca}, \mathrm{Na}) \\
\text { and }>\mathrm{C} 14(\mathrm{Zn}) \text {. Structured in } \\
\text { diacid salts. }\end{array}$ \\
\hline $2874-2870$ & n.a. & n.a. & $v_{s} \mathrm{CH}_{3}$ & \\
\hline $\begin{array}{l}2856-2850 \text { Na salts } \\
2851 \text { Ca and Zn salts }\end{array}$ & $\begin{array}{c}2863 \mathrm{Na} \\
2860,2850 \mathrm{Ca} \\
2867,2851 \mathrm{Zn}\end{array}$ & $\begin{array}{l}2858,2848 \mathrm{Na} \\
2862,2849 \mathrm{Ca} \\
2867,2850 \mathrm{Zn}\end{array}$ & $v_{\mathrm{s}} \mathrm{CH}_{2}$ & $\begin{array}{l}\text { Downshifted }\left(\sim 5 \mathrm{~cm}^{-1}\right) \text { in } \\
\text { monoacid Na salts, for }>C 9 \text {. Split } \\
\text { into two components } \\
\text { in diacid salts }\end{array}$ \\
\hline $\begin{array}{c}1628 \text { (br) Ca salt } \\
1617-1619 \text { Zn salts } \\
\text { C12-C24 }\end{array}$ & $1607 \mathrm{Zn}$ & $1616 \mathrm{Zn}$ & $\delta \mathrm{H}-\mathrm{O}-\mathrm{H}$ (cryst. water) & $\begin{array}{l}\text { In Ca and higher } \mathrm{Zn} \text { monoacid } \\
\text { salts. Only in zinc diacid salts. }\end{array}$ \\
\hline $\begin{array}{c}1560 \text { Na salts } \\
\text { 1579, } 1542 \text { Ca salts } \\
1551,1532 \text { Zn salts, C8, C9 } \\
1540 \text { (br) Zn salts C10-C24 }\end{array}$ & $\begin{array}{c}1563 \mathrm{Na} \\
1581,1544 \mathrm{Ca} \\
1551,1537 \mathrm{Zn}\end{array}$ & $\begin{array}{c}1575 \mathrm{Na} \\
1581,1542 \mathrm{Ca} \\
1556,1534 \mathrm{Zn}\end{array}$ & $v_{a s} \mathrm{COO}^{-}$ & $\begin{array}{l}\text { Singlet for } \mathrm{Na} \text { and higher } \mathrm{Zn} \text { salts. } \\
\text { Doublet for } \mathrm{Ca} \text { and lower } \mathrm{Zn} \text { salts. }\end{array}$ \\
\hline $\begin{array}{l}1472-1459 \text { Na salts } \\
1473 \text { Ca salts } \\
1467-1464, \text { Zn salts }\end{array}$ & $\begin{array}{c}1463,14447,1432, \mathrm{Na} \\
1468,1455,1431,1411 \mathrm{Ca} \\
1467,1460,1450 \mathrm{Zn}\end{array}$ & $\begin{array}{c}1463,1405 \mathrm{Na} \\
1468,1434,1420 \mathrm{Ca} \\
1468,1456 \mathrm{Zn}\end{array}$ & $\delta \mathrm{CH}_{2}$ scissoring & $\begin{array}{l}\text { Single peak, a stable frequency for } \\
\text { Ca and higher monoacid Zn salts. } \\
\text { Four- or three-fold structuring in } \\
\text { diacid salts. }\end{array}$ \\
\hline $1458 \mathrm{Zn}$ salts & n.a. & n.a. & $\delta_{a s} \mathrm{CH}_{3}$ & $\begin{array}{c}\text { Overlapped in Na salts; } \\
\text { undetectable in Ca salts. } \\
\text { Detectable as unresolved shoulder } \\
\text { in Zn lower salts. }\end{array}$ \\
\hline $\begin{array}{c}1423 \text { Na salts } \\
1433,1411 \text { Ca salts } \\
1410,1399 \text { Zn salts C8, C9 } \\
1398 \text { Zn salts C10-C24 }\end{array}$ & $\begin{array}{c}1416 \mathrm{Na} \\
1436,1405 \mathrm{Ca} \\
1412,1399 \mathrm{Zn}\end{array}$ & $\begin{array}{c}1434 \mathrm{Na} \\
1431,1411 \mathrm{Ca} \\
1407,1398 \mathrm{Zn}\end{array}$ & $v_{s} \mathrm{COO}^{-}$ & $\begin{array}{l}\text { Singlet for } \mathrm{Na} \text { and higher } \mathrm{Zn} \text { salts. } \\
\text { Doublet for } \mathrm{Ca} \text { and lower } \mathrm{Zn} \text { salts. }\end{array}$ \\
\hline- & n.a. & & $\begin{array}{c}\delta_{S} \mathrm{CH}_{3} \text { ('umbrella' } \\
\text { vibration) }\end{array}$ & $\begin{array}{l}\text { Undetectable in most } \\
\text { monoacid salts }\end{array}$ \\
\hline $\begin{array}{l}1400-1351 \text { Na salts } \\
1380-1287 \text { Ca salts } \\
1375-1260 \text { Zn salts }\end{array}$ & $\begin{array}{c}1356 \mathrm{Na} \\
1359,1332 \mathrm{Ca} \\
1366 \mathrm{Zn}\end{array}$ & $\begin{array}{c}1339 \mathrm{Na} \\
1343,1318 \mathrm{Ca} \\
1353 \mathrm{Zn}\end{array}$ & $\tau \mathrm{CH} 2$ & $\begin{array}{l}\text { Progressions of } 4 \text { or } 5 \text { sub-bands in } \\
\text { monoacid salts. Singlet or doublet } \\
\text { in diacid salts. }\end{array}$ \\
\hline $\begin{array}{l}1341-1180 \text { Na salts } \\
1278-1190 \text { Ca salts } \\
1250-1045 \text { Zn salts }\end{array}$ & $\begin{array}{c}1293,1200 \mathrm{Na} \\
1293,1261,1247,1217, \\
1201 \mathrm{Ca} \\
1303,1207 \mathrm{Zn}\end{array}$ & $\begin{array}{c}1316,1288,1273,1253 \\
1233,1195 \mathrm{Na} \\
1286,1251,1200 \mathrm{Ca} \\
1285,1243 \mathrm{Zn}\end{array}$ & $w \mathrm{CH} 2$ & $\begin{array}{l}\text { Progressions following the } \mathrm{n} / 2 \\
\text { pattern ( } \mathrm{n}=\text { total carbon atoms) in } \\
\mathrm{Na} \text { and Ca salts. } \\
\text { Sub-bands in Zn salts. }\end{array}$ \\
\hline $\begin{array}{l}1185-1100 \mathrm{Na} \\
1114 \mathrm{Ca} \\
1067-1105 \mathrm{Zn}\end{array}$ & 1100 & 1100 & Unassigned & $\begin{array}{l}\text { Weak single band; up-shifting with } \\
\text { longer carbon chains in monoacid } \\
\text { Zn salts. Single band; not observed } \\
\text { in Na and Zn C8di salts. }\end{array}$ \\
\hline $855-849$ & & & $\delta \mathrm{CH}_{3}+\mathrm{vC}-\mathrm{C}$ & $\begin{array}{l}\text { Not observed in monoacid zinc } \\
\text { and diacid soaps. }\end{array}$ \\
\hline $\begin{array}{l}725-717,698 \\
721 \text { Ca salts } \\
747,723 \text { Zn salts }\end{array}$ & & & $\rho \mathrm{CH} 2$ & $\begin{array}{l}\text { Doublet for } \mathrm{Na} \text { and } \mathrm{Zn} \text { salts; single } \\
\text { peak for Ca salts. }\end{array}$ \\
\hline
\end{tabular}

v: stretching vibration; vs: symmetric stretching; $v_{a s}$ : antisymmetric stretching; $\delta$ : bending vibration; $\delta_{s}$ : symmetric bending; $\delta_{a s}$ : antisymmetric bending; $\delta_{\mathrm{ip}}$ : in-plane bending; $\delta_{\mathrm{oop}}$ : out-of-plane bending; $\tau$ : twisting vibration; $\rho$ : rocking vibration; $w$ : wagging vibration. 


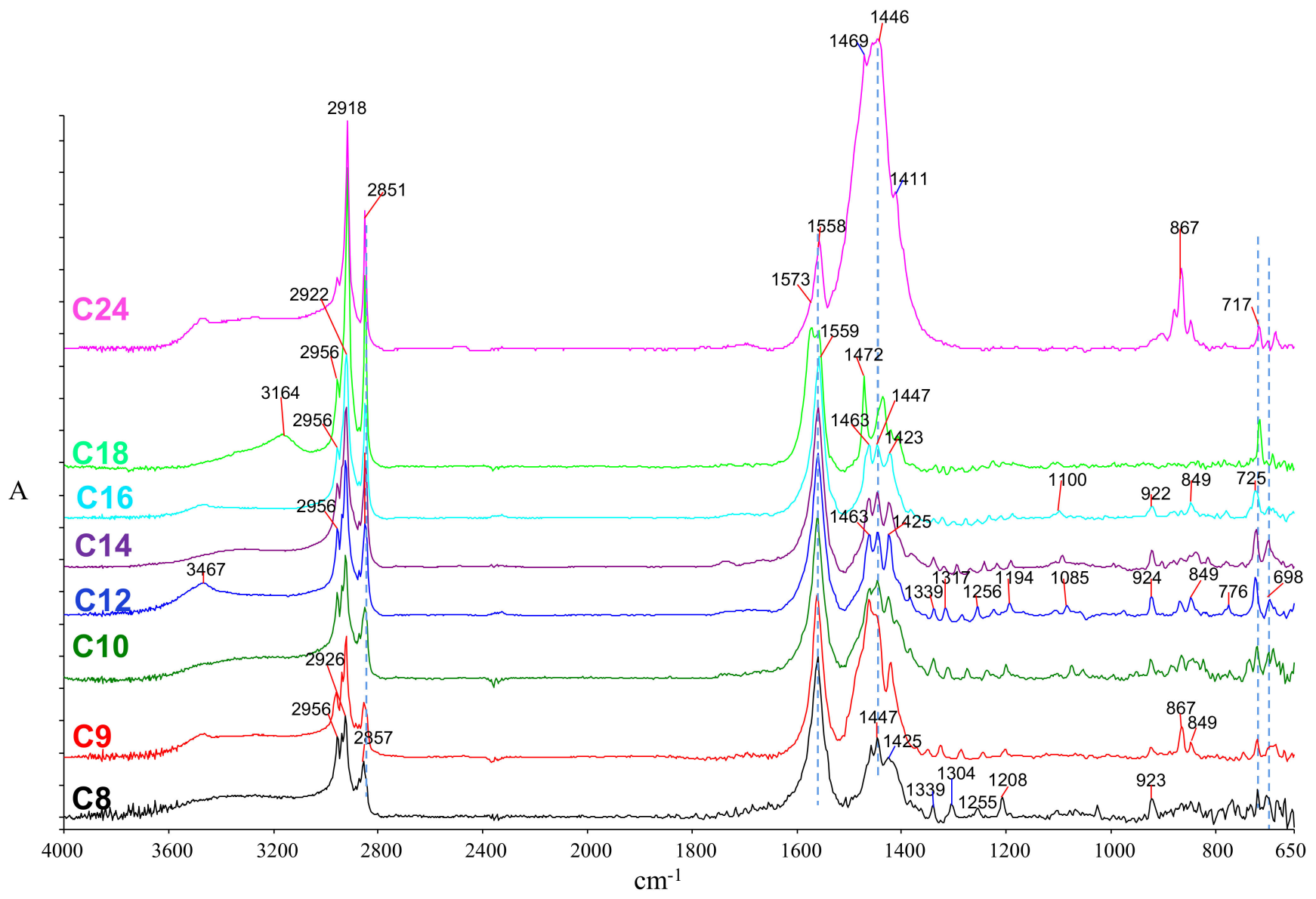

(a)

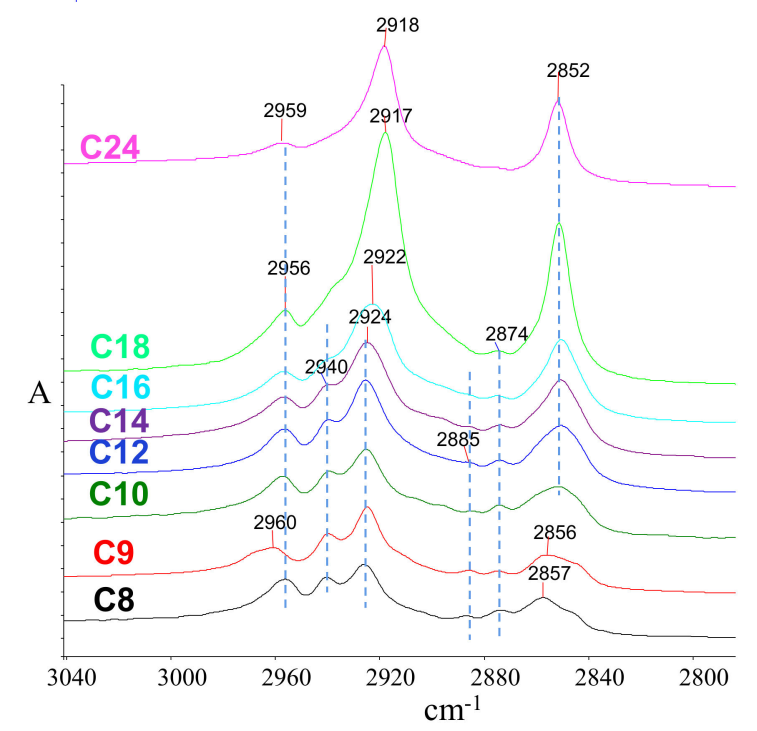

(b)

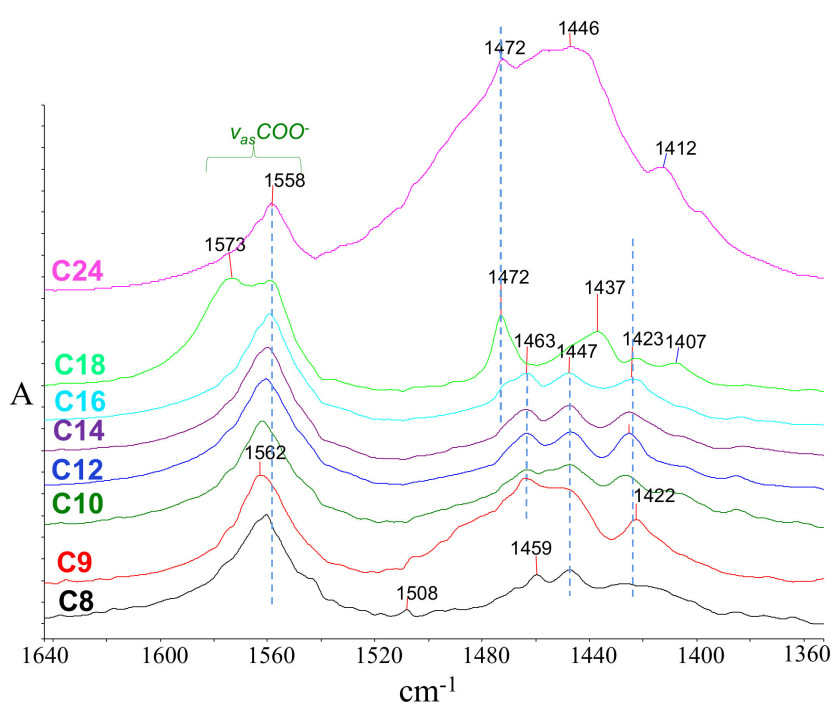

(c)

Figure 5. Infrared spectra of fatty acid sodium salts. (a) Full spectrum; (b) C-H stretching region; and (c) carboxylate region. In all spectra: C8, sodium octanoate; C9 sodium nonanoate; C10, sodium decanoate; C12, sodium dodecanoate; C14, sodium tetradecanoate; C16, sodium hexadecanoate; C18, sodium octadecanoate; C24, sodium tetracosanoate; C9 and C24 are contaminated with sodium carbonate (intense peaks at $\sim 1450$ and $867 \mathrm{~cm}^{-1}$ ). The negative peaks at $\sim 2380 \mathrm{~cm}^{-1} \mathrm{correspond}$ to carbon dioxide as a result of improper background subtraction. 
The sodium soaps can be correlated with the ionic structure (Figure 4a), showing carboxylate maxima at $\sim 1560 \mathrm{~cm}^{-1}$ and $1425 \mathrm{~cm}^{-1}$ for $v_{\text {as }} \mathrm{COO}^{-}$and $v_{\mathrm{s}} \mathrm{COO}^{-}$, respectively [149]. Specifically, for sodium stearate $(\mathrm{C} 18 \mathrm{Na})$, the antisymmetric band appears as a doublet at 1573 and $1559 \mathrm{~cm}^{-1}$ (Figure 5c), possibly due to two different sub-cell arrangements [153]. Interestingly, deviations of the above are observed in cases where sodium salts co-crystallize with their corresponding FA. A unified acid-soap carbonyl stretch is observed in above, at $\sim 1740 \mathrm{~cm}^{-1}$, attributed to a hydrogen bonding decrease combined with changes in acid-soap conformations [153].

For the calcium soaps, double-splitting is observed for all FAMS at 1580 and $1542 \mathrm{~cm}^{-1}$ $\left(v_{\mathrm{as}} \mathrm{COO}^{-}\right)$and 1435 and $1419 \mathrm{~cm}^{-1}\left(v_{\mathrm{s}} \mathrm{COO}^{-}\right)$, indicating two different denticities in the coordination structure (Figure 6). Splitting of this type has been reported for precipitated calcium soap molecular units in bulk acquiring three-dimensional molecular geometry [84,154]. On the other hand, for two-dimensional calcium soap layers, such as those formed through the interaction of fatty acids with calcium-containing surfaces, the doublet becomes a singlet $\left(1550 \mathrm{~cm}^{-1}\right.$ for the antisymmetric band) [155]. Since the calcium soaps as reaction products of free fatty acids with calcium carbonate are generally expected in specific archaeological contexts $[27,143,144]$, the above maxima are generally expected and have been in some instances observed [8,9].

The zinc salts (Figure 7) in most cases show single, relatively broadened carboxylate bands at $1540\left(v_{\mathrm{as}} \mathrm{COO}^{-}\right)$and $1398 \mathrm{~cm}^{-1}\left(v_{\mathrm{s}} \mathrm{COO}^{-}\right)$. However, in the case of the shorterchain fatty acid salts $\left(\mathrm{C}_{2} \mathrm{Zn}\right.$ and $\left.\mathrm{C}_{10} \mathrm{Zn}\right)$, splitting is observed at 1550 and $1532 \mathrm{~cm}^{-1}$ $\left(v_{\mathrm{as}} \mathrm{COO}^{-}\right)$, and 1410 and $1399 \mathrm{~cm}^{-1}\left(v_{\mathrm{s}} \mathrm{COO}^{-}\right)[72,73,155]$.

As a general remark, the splitting in both asym- and sym-carboxylate bands of the divalent metal salts into doublets has been previously observed and attributed to bidentate and unidentate salt types (Figure 4) [154,156]; the splitting can be as large as $\sim 40 \mathrm{~cm}^{-1}$ for the calcium salts, while it is significantly smaller for the zinc salts. The trends in antisymmetric and symmetric carboxylate maxima for various sodium, calcium, and zinc soaps are shown in Figure S4. A significant feature of the carboxylate bands is the separation $\Delta v$ between the antisymmetric and symmetric peaks, considered to depend on factors such as the type of metal, the ligand, and the coordination type and denticity $[157,158]$, the packing of chains [158-161], as well as the molecular environment (solvent, or other materials in the molecular environment) [73,160]. As shown in Figure S4 (values drawn from spectra in Figure 4, Figure 5, and Figure 7), the $\Delta v$ value in the lower-symmetry sodium soaps is generally expected to be $\sim 137 \mathrm{~cm}^{-1}$, while for the higher-symmetry calcium and zinc, this is expected to be higher at $142-144 \mathrm{~cm}^{-1}$ [158].

The calcium and zinc salts show similar $\Delta v$ values at $143-144 \mathrm{~cm}^{-1}$ (with the exception of the C24 salt), suggesting higher-symmetry bidentate coordination. The differences in separation values between the sodium and the divalent salts are marginal as they are comparable with the wavenumber uncertainty limit $\left(4 \mathrm{~cm}^{-1}\right.$, see Materials and Techniques). Our data shows a deviation for the C8Zn and C9Zn salts, showing $\Delta v$ values at $131 \mathrm{~cm}^{-1}$.

As a general remark, the carboxylate bands can be significantly broadened and shifted so that $\Delta v$ decreases when soaps are formed in an amorphous molecular vicinity (as is the case of metal soaps formed in paintings with the glassy molecular environment of the binding medium) $[6,73,160]$. 


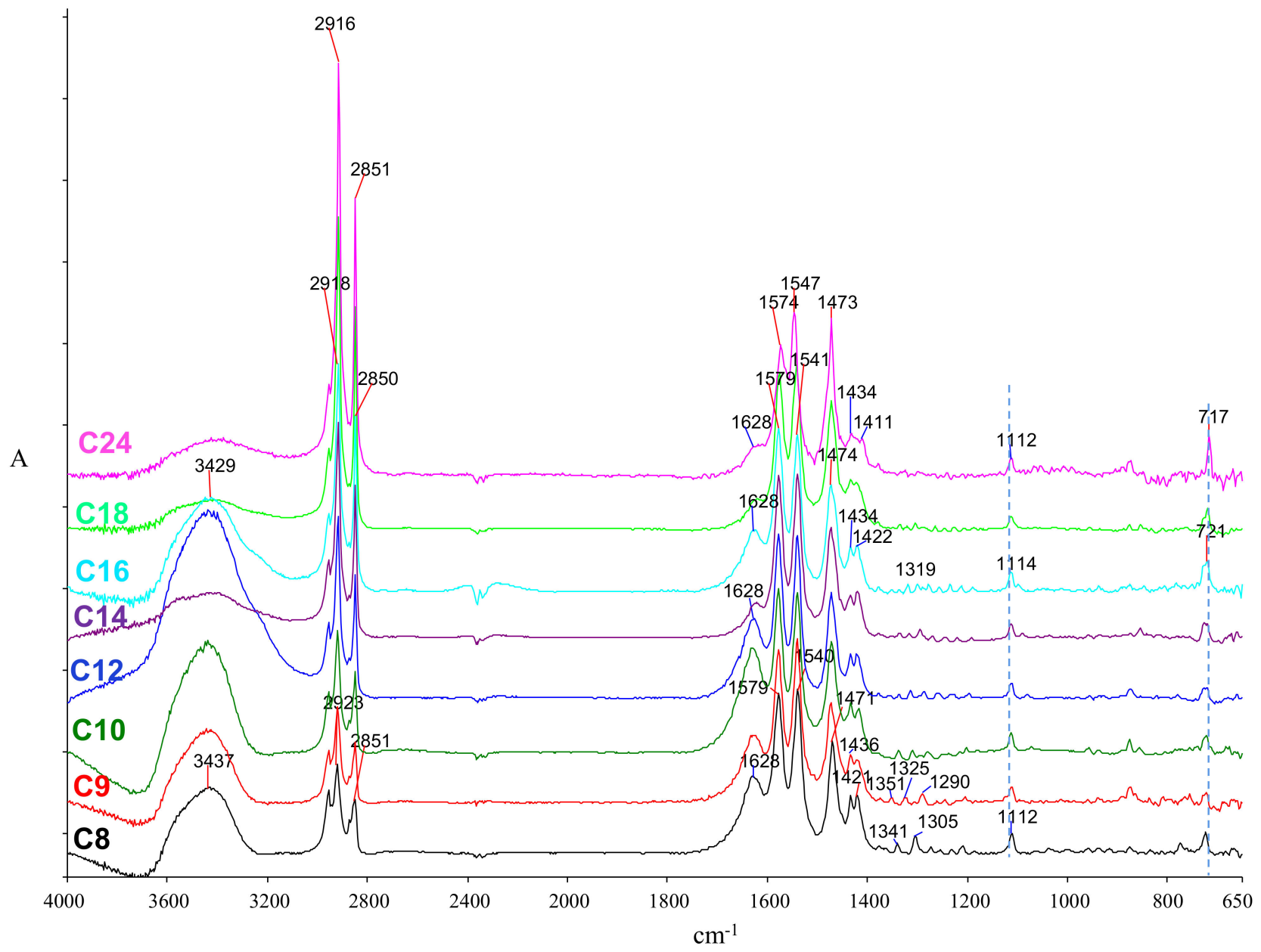

(a)

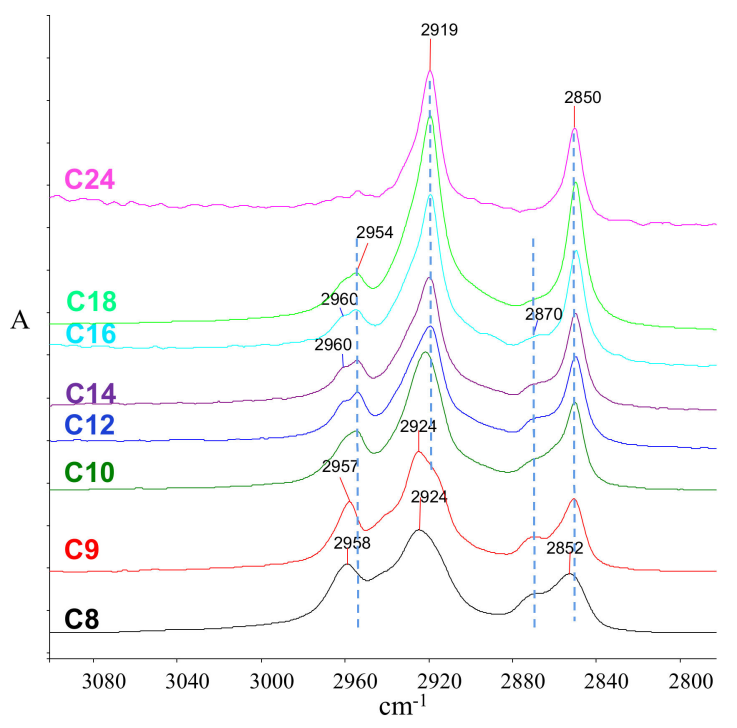

(b)

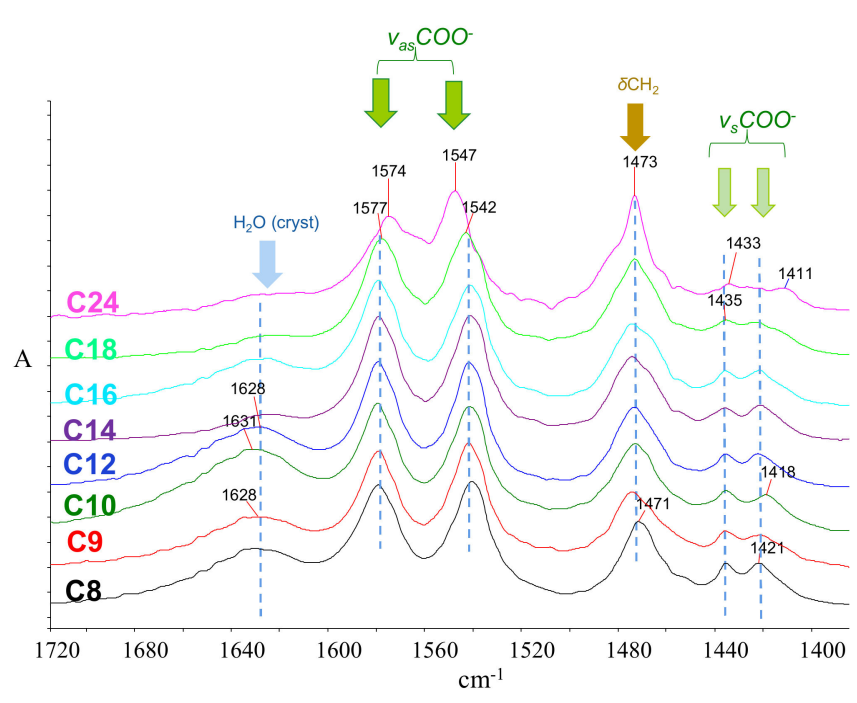

(c)

Figure 6. Infrared spectra of fatty acid calcium salts. (a) Full spectrum; (b) C-H stretching region; and (c) carboxylate region. In all spectra: C8, calcium octanoate; C9 calcium nonanoate; $\mathrm{C} 10$, calcium decanoate; $\mathrm{C} 12$, calcium dodecanoate; $\mathrm{C} 14$, calcium tetradecanoate; $\mathrm{C} 16$, calcium hexadecanoate; $\mathrm{C} 18$, calcium octadecanoate; $\mathrm{C} 24$, calcium tetracosanoate. Contaminated with small amounts of calcium carbonate (peaks at $\sim 1435$ and $874 \mathrm{~cm}^{-1}$ ). The negative peaks at $\sim 2380 \mathrm{~cm}^{-1}$ correspond to carbon dioxide as a result of improper background subtraction. 


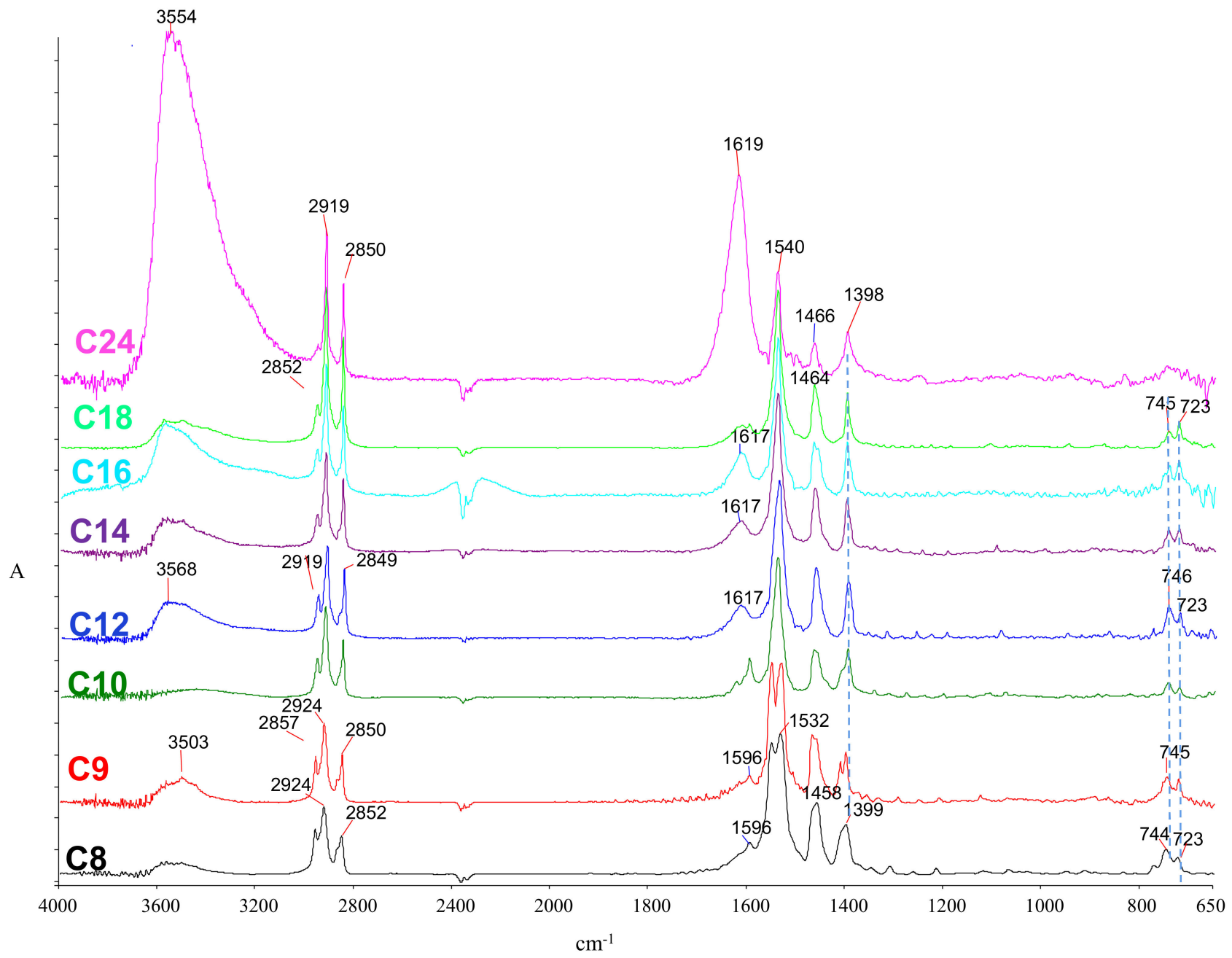

(a)

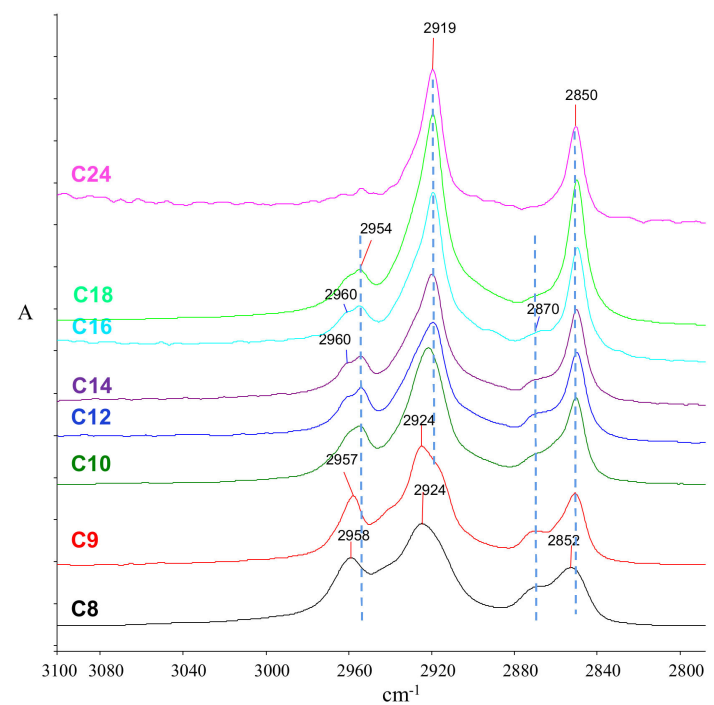

(b)

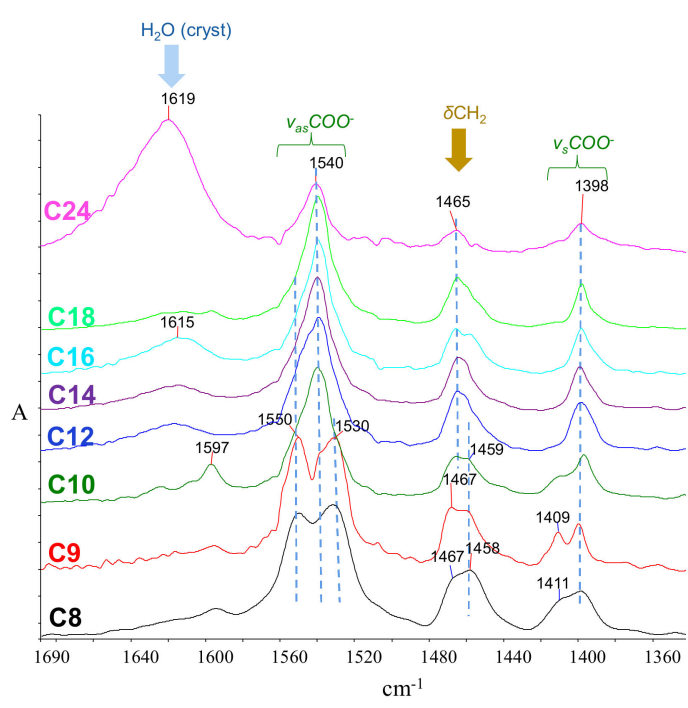

(c)

Figure 7. Infrared spectra of fatty acid zinc salts. (a) Full spectrum; (b) C-H stretching region; and (c) carboxylate region. In all spectra: $\mathrm{C} 8$, zinc octanoate; $\mathrm{C} 9$ zinc nonanoate; $\mathrm{C} 10$, zinc decanoate; $\mathrm{C} 12$, zinc dodecanoate; $\mathrm{C} 14$, zinc tetradecanoate; $\mathrm{C} 16$, zinc hexadecanoate; $\mathrm{C} 18$, zinc octadecanoate; $\mathrm{C} 24$, zinc tetracosanoate. The negative peaks at $2380 \mathrm{~cm}^{-1} \mathrm{correspond}$ to carbon dioxide as a result of improper background subtraction. 


\section{The C-H Vibrations}

As a general remark, the $\mathrm{CH}_{2}$ antisymmetric stretching band in FAMS shows fewer components and lower variability in their maxima than those in FAs. Spectra are shown in Figure $3 b$, Figure $4 b$, and Figure $5 b$, for the three metal salts, respectively. For the carbons closer to the carboxylate group, maxima appear at higher frequencies $\left(2945-2935 \mathrm{~cm}^{-1}\right)$, while for the more distanced ones, these are downshifted at approximately $2920 \mathrm{~cm}^{-1}$. Notably, for the sodium salts of fatty acids with chains shorter than $\mathrm{C} 14$, the peaks are resolved to $\sim 2957,2940$, and $2920 \mathrm{~cm}^{-1}$. The sym- $\mathrm{CH}_{2}$ stretching typically appears at 2857-2850 $\mathrm{cm}^{-1}$, and the $\mathrm{CH}_{3}$ stretching appears at 2956 (asym-) and $2874 \mathrm{~cm}^{-1}$ (sym-).

The methylene bending vibrations were found at $1460-1470 \mathrm{~cm}^{-1}$ (Na salts), $1468-1473 \mathrm{~cm}^{-1}$ (Ca salts), and 1456-1467 $\mathrm{cm}^{-1}$ (Zn salts), respectively, while the methyl bending is either very weak or not observed at all. This region is shown in Figure 3c, Figure $4 \mathrm{c}$, and Figure $5 \mathrm{c}$. The twisting vibrations are observed at $1400-1260 \mathrm{~cm}^{-1}$ as progressions of four or five peaks, which are quite intense for $\mathrm{Ca}$ and $\mathrm{Zn}$ salts. The wagging vibrations are also observed as progressions, generally at $1270-1180 \mathrm{~cm}^{-1}$, similar to those of the corresponding FA, although relatively weaker and at numbers that follow the $n / 1$ pattern (where $\mathrm{n}$ is the number of total carbon atoms). The weak bands at $870-860 \mathrm{~cm}^{-1}$ are assigned to the coupling between $\delta \mathrm{CH}_{3}$ and $v \mathrm{C}-\mathrm{C}$ [84]. Finally, the splitting of rocking vibrations in the form of doublets at $745-723 \mathrm{~cm}^{-1}$ is observed only for zinc salts (Figure 7a). In most other cases, this is elusive, reflecting a misalignment of the hydrocarbon chains, possibly induced by the big difference between the ionic group and hydrocarbon chain polarities.

Based on the recorded spectra, the above results refer to the pure materials, and therefore 'ideal' situations in the absence of organic additives, inorganic materials, etc.; spectra of soaps present in 'real' samples may differ in their subtle features such as progressions and splitting. Metal soaps on surfaces may acquire liquid crystal character [138]; in the case of a divalent metal (calcium, zinc), the hydrocarbon chains arrange on both sides of the metal ion plane. When this arrangement is unperturbed (for instance, in pure salts), alkyl chains longer than $\mathrm{C} 12$ align well to show the progressions and splittings, as described above. However, the non-polar liquid crystal layer may occasionally accommodate foreign compounds of small MW (solvents, degradation products, etc.) that may disrupt the ordered chain alignment and, therefore, diminish the intensity of these features $[138,145,161]$. In these cases, the appearance of progressions and split peaks can be considered as a measure of phase purity. Nevertheless, more research is needed to investigate the crystallization phenomena of metal soaps in various environments.

\subsection{Infrared Spectra of Selected Diacids and Their Metal Salts \\ 2.3.1. Azelaic and Suberic Acids}

During the last 50 years, research has shown that diacids, especially nonanedioic and octanedioic (azelaic, C9di, and suberic, C8di, respectively) acids, are standard oxidation products of polyunsaturated fatty acids $[75,84,162]$. They are commonly detected in organic remains of archaeological objects containing unsaturated oils [1,2,10,163-165], and in oil-based paintings [76,166-169]. Specific features in diacid spectra (shown in Figure 8, maxima and assignments in Table 1) can be helpful in their identification and distinction from monoacids.

The acidic carbonyl absorption for diacids is observed at $\sim 1695 \mathrm{~cm}^{-1}$, downshifted compared to monoacids due to more efficient hydrogen bonding between carboxyl groups. According to their structural characteristics, carboxyl groups are associated with intense intermolecular hydrogen bonding, resulting in monoclinic crystals. As seen in Figure 1b,c, the structures differ depending on odd- and even-numbered chains [91,170-173]. 


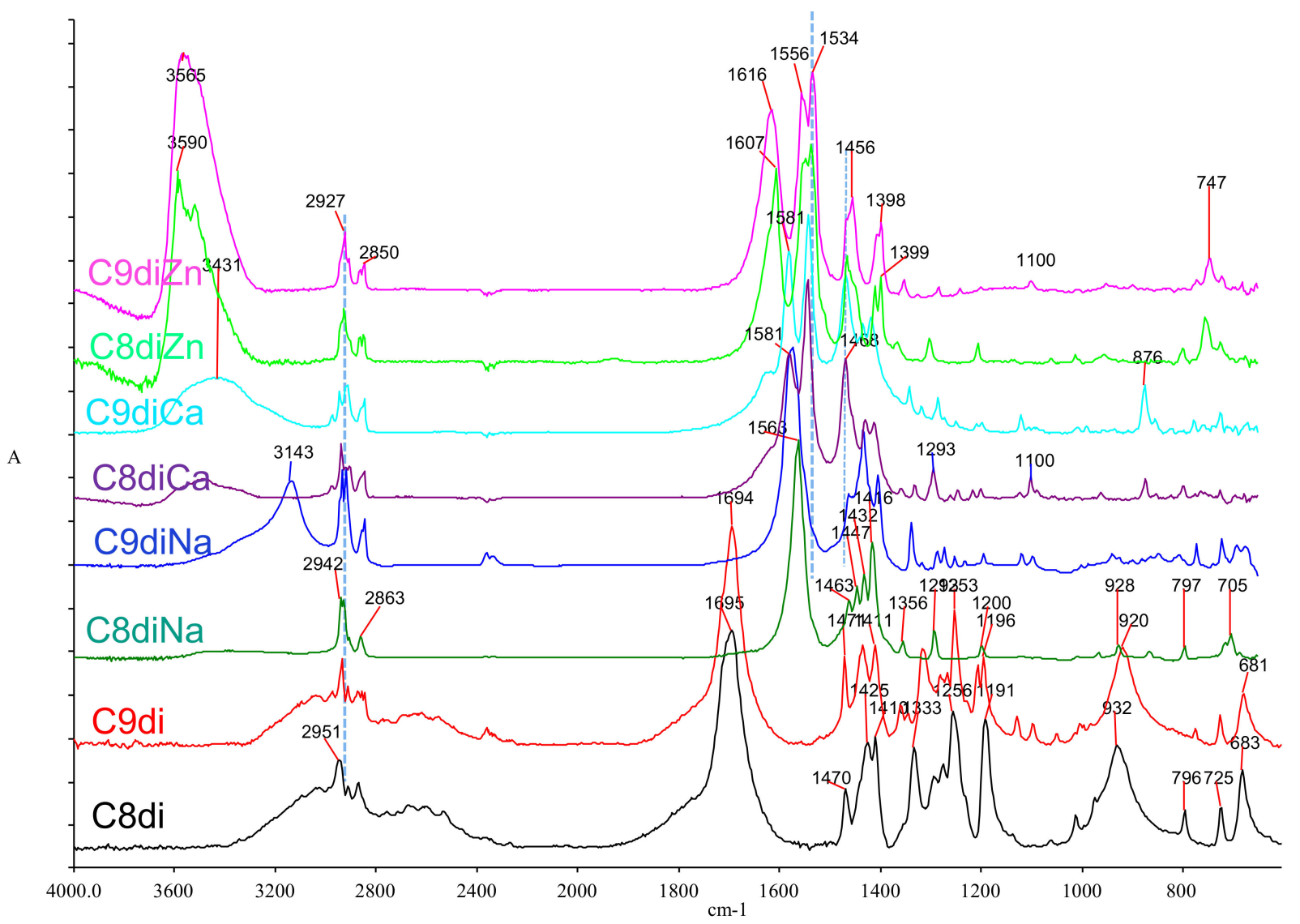

(a)

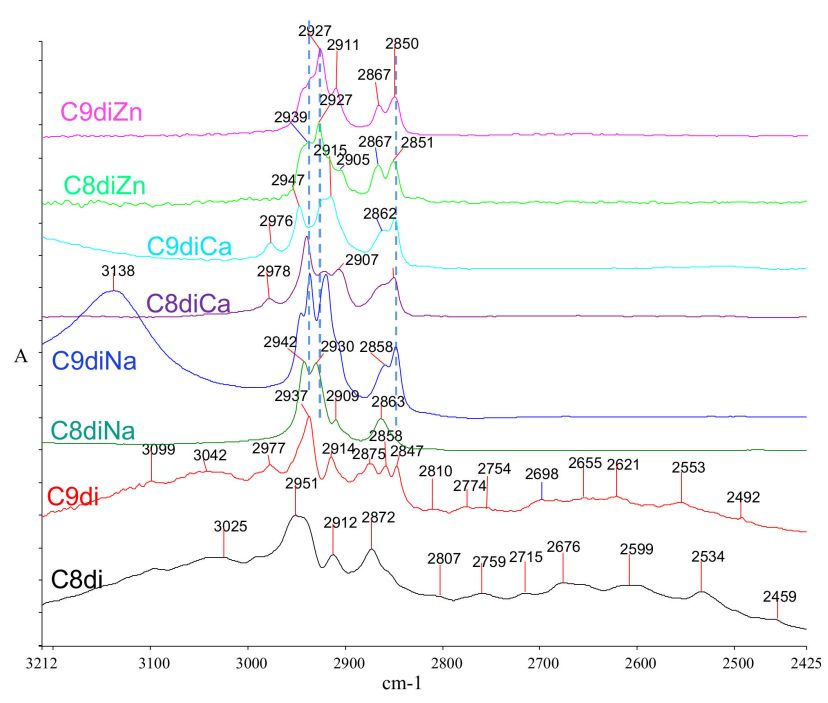

(b)

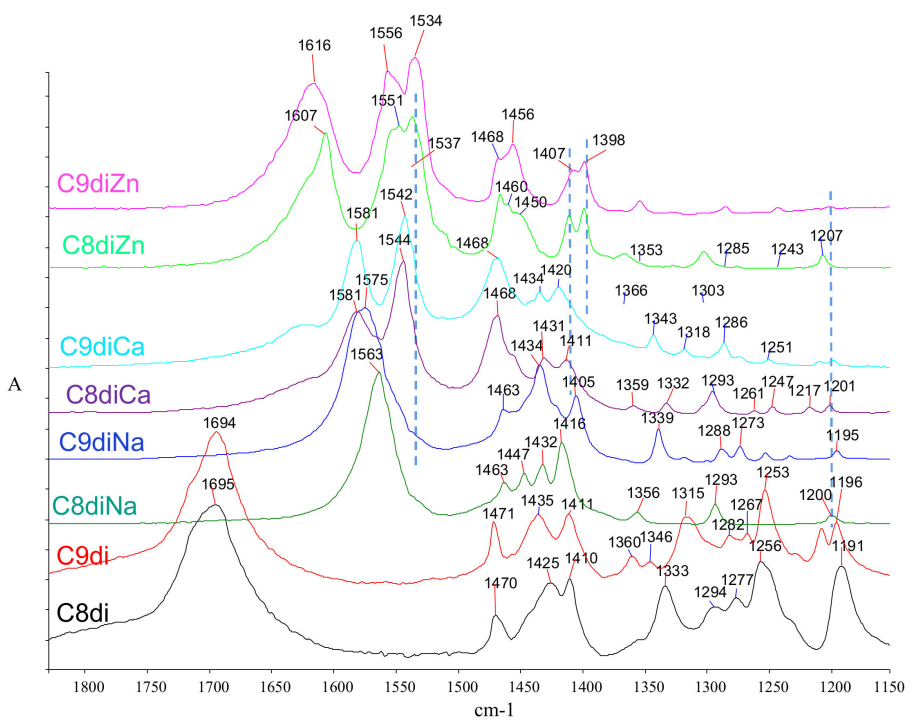

(c)

Figure 8. Infrared spectra of selected dicarboxylic acids and their sodium, calcium, and zinc salts. (a) Full spectrum; (b) C-H stretching region; and (c) 1800-1150 region. In all spectra: C8di, octanedioic acid (suberic acid); C9di, nonanedioic acid (azelaic acid); C8diNa, C8diCa, and C8diZn, sodium, calcium, and zinc octanedioates (suberates), respectively; C9diNa, C9diCa, and C9diZn, sodium, calcium, and zinc nonanedioates (azelates), respectively.

Similar to monoacids, the hydroxyl stretching is typically observed as a broad band, spanning 3200-2800 $\mathrm{cm}^{-1}$. On the other hand, and in contrast to monoacids, the hydroxyl 
dimer band is structured, showing at least seven characteristic satellite bands spanning the $2810-2459 \mathrm{~cm}^{-1}$ region (Figure 8 b).

Besides the expected absence of methyl bands, which can be seen as a diagnostic feature in spectra, the methylene stretching region is characteristically more complex than those of monoacids with split antisymmetric and symmetric bands. In the case of azelaic acid, this is more intense with both the $v_{a s} \mathrm{CH}_{2}$ and $v_{s} \mathrm{CH}_{2}$ bands triply resolved at $2977-2914 \mathrm{~cm}^{-1}$ and $2875-2847 \mathrm{~cm}^{-1}$, respectively (Figure $8 \mathrm{~b}$ ). The difference in the $\mathrm{CH}_{2}$ stretching bands between the two acids can be attributed to a different crystal geometry allowing polymorphism in their monoclinic structures based on parallel and vertical orientations among the carboxyl group planes, resulting in different crystal packing between even- and odd-numbered diacids [90,91,115,172-179].

The methylene bending vibrations are observed as doubly split bands at $\sim 1470$ and $1410 \mathrm{~cm}^{-1}$ (Figure 8c). The twisting vibrations are triply split $\left(1360,1346\right.$, and $1315 \mathrm{~cm}^{-1}$ ) in azelaic acid, while they show a uniform peak in suberic acid $\left(1333 \mathrm{~cm}^{-1}\right)$. The wagging vibrations are triply split in both acids at $1290-1250 \mathrm{~cm}^{-1}$. The rocking vibration appears as two medium-weak peaks at $\sim 796$ and $725 \mathrm{~cm}^{-1}$ for both acids with no evident splitting.

The hydroxyl bending $(\delta \mathrm{C}-\mathrm{O}-\mathrm{H})$ appears as an obscure band at 1425 and $1435 \mathrm{~cm}^{-1}$, for C8di and C9di, respectively [115] (Figure 8c). The acidic carbonyl C-O stretch is a very weak doublet at 1105 and $1098 \mathrm{~cm}^{-1}$ for azelaic, while it is not observed for suberic acid (Figure 8a). Finally, the out-of-plane C-O-H bending is shown at $681 \mathrm{~cm}^{-1}$ for both acids, while its dimer counterpart appears as a broad band at 932 (suberic) and $920 \mathrm{~cm}^{-1}$ (azelaic).

\subsubsection{Diacid Metal Salts}

In the case of diacid salts, most research has been done in the art paintings context. However, the literature for their systematic infrared spectra is limited [84,180], despite the fact that the corresponding fatty acids are widespread in oil paintings and specific archaeological samples, and the formation of their salts through ion exchange is more than expected. As a result of their difunctional character, diacid metal salts may associate with divalent metal ions with both their ionic ends; this way, metal-coordinated ionic networks can be formed with an ionomer character $[6,75,145]$, which through their diminished mobility may act as a stabilizing means for the medium. This structural phenomenon has been proposed as a 'self-repair' mechanism by diacid salts which mitigates the detrimental effect caused by soap formation in paintings $[84,145]$. Although diacids have been investigated in lipid-containing archaeological samples [164], diacid salt formation has not been reported, and therefore, no data exist for similar phenomena in the various archaeological environments.

Similarly, with the previous cases, suberate (C8 dicarboxylate, or C8di), and azelate (C9 dicarboxylate, or C9di) salts with sodium, calcium, and zinc were also synthesized in the laboratory (see Materials and Methods). As seen in the spectra of Figure 8, the main infrared features of suberates and azelates (listed in Table 2) are similar to those of monoacids, although with subtle, but important differences. Specifically, the zinc salts appear in their hydrated form, with crystalline water observed at $3560-3520 \mathrm{~cm}^{-1}$ and 1607 , and 1616 for C8di and C9di, respectively (Figure 8a). The carboxylate bands are intense and characteristic, appearing as an asym-/sym- pair (Figure 8c). For the sodium salts, a pair of single carboxylate peaks are observed at 1563-1575 (asym-) and 1416-1405 (sym-) (Figure 8c). On the other hand, each vibration is doubly split at 1575-1544 (asym-) and 1431-1410 (sym-) for calcium and 1551-1534 (asym-) and 1412-1400 (sym-) for zinc. By analogy to monoacid salts, the splitting can be attributed to differences in coordination geometry. The splitting value $\left(\Delta v_{\text {split }}\right)$ is $40 \mathrm{~cm}^{-1}$ for the calcium salts, while it is significantly smaller, $\sim 18 \mathrm{~cm}^{-1}$, for the zinc salts.

Most methylene bands in diacid salts are characteristically structured, possibly as a result of interactions in the crystalline phase (Figure $\mathrm{S1b}, \mathrm{c}$ ). The antisymmetric $\mathrm{CH}_{2}$ stretching band is split into four components for the calcium salts at $2978-2907 \mathrm{~cm}^{-1}$, four components for sodium, and three for zinc salts at 2940-2905 $\mathrm{cm}^{-1}$ (see Figure 8b). The 
$\mathrm{CH}_{2}$ bending band (scissoring) is also structured at $1463-1405 \mathrm{~cm}^{-1}$, with the suberate band being more extended than the azelate. The methylene twisting is observed as a single peak at $\sim 1360 \mathrm{~cm}^{-1}$ for most salts, while wagging appears as a progression at $1318-1195 \mathrm{~cm}^{-1}$, significantly more extended for the azelates. Finally, the $\mathrm{CH}_{2}$ rocking is observed at $725-705 \mathrm{~cm}^{-1}$ for the sodium and calcium diacid salts and $747,723 \mathrm{~cm}^{-1}$ for the zinc salts.

\section{Materials and Methods}

\subsection{Materials}

Fatty acids were purchased from Sigma-Aldrich (Kenilworth, NJ, USA): octanoic, or caprylic $\left(\mathrm{CH}_{3}\left(\mathrm{CH}_{2}\right)_{6} \mathrm{COOH}\right.$ or $\left.\mathrm{C} 8: 0, \geq 99 \%\right)$, nonanoic, or pelargonic $\left(\mathrm{CH}_{3}\left(\mathrm{CH}_{2}\right)_{7} \mathrm{COOH}\right.$ or C9:0, $\geq 99 \%)$, decanoic, or capric $\left(\mathrm{CH}_{3}\left(\mathrm{CH}_{2}\right)_{8} \mathrm{COOH}\right.$ or $\left.\mathrm{C10:0,}>98.0 \%\right)$, dodecanoic, or lauric $\left(\mathrm{CH}_{3}\left(\mathrm{CH}_{2}\right)_{10} \mathrm{COOH}\right.$ or C12:0, $\left.\geq 99 \%\right)$, tetradecanoic, or myristic $\left(\mathrm{CH}_{3}\left(\mathrm{CH}_{2}\right)_{12} \mathrm{COOH}\right.$ or $\mathrm{C} 14: 0, \geq 99 \%)$, hexadecanoic, or palmitic $\left(\mathrm{CH}_{3}\left(\mathrm{CH}_{2}\right)_{14} \mathrm{COOH}\right.$ or $\left.\mathrm{C} 16: 0, \geq 99 \%\right)$, octadecanlic, or stearic $\left(\mathrm{CH}_{3}\left(\mathrm{CH}_{2}\right)_{16} \mathrm{COOH}\right.$ or $\left.\mathrm{C} 18: 0, \geq 98.5 \%\right)$, tetracosanoic, or lignoceric $\left(\mathrm{CH}_{3}\left(\mathrm{CH}_{2}\right)_{22} \mathrm{COOH}\right.$ or $\left.\mathrm{C} 24: 0, \geq 99 \%\right)$, octanedioic, or suberic $\left(\mathrm{C}_{6} \mathrm{H}_{12}(\mathrm{COOH})_{2}\right.$ or $\mathrm{C} 8 \mathrm{di}$, $98 \%)$, and nonanedioic, or azelaic $\left(\mathrm{C}_{7} \mathrm{H}_{14}(\mathrm{COOH})_{2}\right.$ or $\left.\mathrm{C} 9 \mathrm{di}, 98 \%\right)$.

Moreover, additional material and reagents were acquired as follows: sodium hydroxide (Sigma-Aldrich $>88 \%$ ), water (Honeywell, Charlotte, NC, USA, HPLC grade), calcium chloride (anhydrous, Sigma-Aldrich, $\geq 93 \%$ ), zinc chloride (Sigma-Aldrich, $\geq 98 \%$ ), ethanol (Merck, Kenilworth, NJ, USA, 99.5\%), chloroform (Sigma-Aldrich, anhydrous, $\geq 99 \%$ ), xylene (mixture of isomers, $\geq 98.5 \%$ ), and acetone (Honeywell, $\geq 99.5 \%$ ).

\subsection{Synthesis of Fatty Acid Metal Salts}

Sodium salts of fatty acids C8:0-C24:0 were prepared by adding $0.1 \mathrm{mmol}$ of the corresponding acids to $1 \mathrm{~mL}$ of sodium hydroxide $0.1 \mathrm{M}$ solutions in ethanol (Honeywell); for the diacid (C8di and C9di) sodium salts, two equivalents of the base was added. The solutions were initially warmed up to $80^{\circ} \mathrm{C}$ on a heating plate, followed by sonication for $15 \mathrm{~min}$. When precipitation was complete, the products were investigated with infrared spectroscopy, where the full conversion to the sodium salt was confirmed for all cases.

The calcium and zinc salts of fatty acids C8:0-C24:0 were prepared by substitution upon mixing aqueous solutions of the corresponding sodium salts (prepared in the previous step and pre-heated on a plate for full solubilization) with aqueous solutions of calcium chloride (Merck, Kenilworth, NJ, USA) and zinc chloride (Sigma-Aldrich, Kenilworth, NJ, USA). The mixtures were sonicated until full conversion was evident through infrared spectroscopy. Infrared spectra of obtained salts (shown in this paper) were in agreement with the literature [71,78,82-85].

\subsection{Fourier Transform Infrared Spectroscopy}

All samples were in powder form and analyzed according to the following procedure: each sample was mixed with $\mathrm{KBr}$, pulverized in a pestle and mortar, and pressed in a $13 \mathrm{~mm}$ disc using a hydraulic press. Infrared spectra of the $\mathrm{KBr}$ discs were recorded in transmission mode using a Perkin Elmer Spectrum GX 1 FTIR spectrometer equipped with a DTGS detector at $4000-650 \mathrm{~cm}^{-1}, 32 \mathrm{scans}$, and $4 \mathrm{~cm}^{-1}$ resolution. Spectra of acids are shown normalized on the carbonyl peak. Spectra of salts are shown normalized on the highest carboxylate peak. Deconvolution of the C-H region $\left(3000-2800 \mathrm{~cm}^{-1}\right)$ was done using the Peak Fitting application of GRAMS/AI (Thermo) software, using a mixed Gaussian (50\%) and Lorentzian (50\%) function, at low sensitivity. In all cases, the standard error was lower than 0.00647 , while $\mathrm{R}^{2}$ was better than 0.9987 .

\section{Conclusions}

The investigation of fatty acids and their metal salts as degradation products of fatty substances in oil paintings and particular archaeological objects can be of high importance. This work explores the usability of infrared spectroscopy for characterizing these 
compounds in related complex samples. The spectra of some typical fatty monoacids, diacids, and their sodium, calcium, and zinc salts are investigated, and their features were examined in terms of their diagnostic usability.

Intermolecular interactions are fundamental for the acidic carbonyl maxima, which downshift from 1713 (for $\mathrm{C} 9$ monoacid) to $1703 \mathrm{~cm}^{-1}$ (C14-C24); these are further downshifted to $1694-1695 \mathrm{~cm}^{-1}$ in diacids. Crystallization and effective molecular associations in the higher members are key factors for this phenomenon, and in some cases, they are inhibited due to unfavorable molecular environments; acidic carbonyl maxima are relatively high, at $\sim 1710 \mathrm{~cm}^{-1}$. The same phenomenon also causes broadening of the dimer band at 945-920 $\mathrm{cm}^{-1}$.

In salts, carboxylate absorptions exist in antisymmetric-symmetric pairs (at 1590-1530 and 1436-1398 $\mathrm{cm}^{-1}$, respectively), often existing in doublets, with separations $(\Delta v)$ depending on the metal. The distinctly higher frequency $\left(181-1579 \mathrm{~cm}^{-1}\right.$ of the calcium salts is helpful for their identification. In these maxima, chain lengths have little or no effect. On the other hand, inefficient crystallization may affect the band envelopes and the separation of both bands. The hydroxyl stretch spans the $3200-2800 \mathrm{~cm}^{-1}$ region of acids with a maximum of around $3000 \mathrm{~cm}^{-1}$. Dimer formation is a typical feature in carboxylic acids, characteristically appearing as a broad maximum involving the stretching vibrations at $2800-2400 \mathrm{~cm}^{-1}$ (in diacids, it appears as a structured band) and as a relatively broad band involving the bending vibrations at $\sim 940 \mathrm{~cm}^{-1}$.

The various $\mathrm{C}-\mathrm{H}$ vibrations significantly depend on monoacid chain lengths and intermolecular interactions among them. In crystallizable samples, splitting in stretching, bending, and rocking vibrations and the characteristic progressions in twisting and wagging for the longer-alkyl chain acids are often a diagnostic asset. Diacids also show splittings but no progressions. Progressions are also expected in metal monoacid soaps, although significantly weaker and more elusive, and therefore, their diagnostic capability is limited.

The rich spectroscopic features of fatty acids and their salts significantly benefit their diagnostic use. A close inspection of an infrared spectrum recorded from complex samples containing fatty acids, or their metal salts, can provide direct evidence for their condition.

Supplementary Materials: The following are available online, Figure S1: Infrared zoomed-in region (1570-1000 $\mathrm{cm}^{-1}$ of crystalline (at room temperature)) of even-numbered monoacids: decanoic (C10:0), dodecanoic (C12:0), tetradecanoic (C14:0), hexadecanoic (C16:0), octadecanoic (C18:0), and tetracosanoic (C24:0). Figure S2: Deconvolution and peak fitting of the $\mathrm{vC}-\mathrm{H}$ band region of (a) octanoic (C8:0), (b) decanoic (C10:0), and (c) octadecanoic (C18:0) acids. Figure S3: Infrared spectrum of palmitic acid (C16:0) (a) as purchased from the vendor, and (b) after a heating (melting)-annealing cycle. Insets: (i) $\mathrm{CH} 2$ wagging region; (ii) $\mathrm{CH} 2$ rocking region.

Author Contributions: Conceptualization, S.C.B.; methodology, S.C.B.; writing-original draft preparation, S.C.B.; supervision, A.F. and S.V.; investigation, A.F. and S.V.; data curation, A.F. and S.V.; writing-review and editing, A.F. and S.V. All authors have read and agreed to the published version of the manuscript.

Funding: This research received no external funding.

Institutional Review Board Statement: Not applicable.

Informed Consent Statement: Not applicable.

Data Availability Statement: The data presented in this study are available on request from the corresponding author.

Conflicts of Interest: The authors declare no conflict of interest.

\section{Abbreviations and Symbols}

FA: fatty acids; FAMS: fatty acid metal salts (or metal soaps); FAE: fatty acid esters; FTIR: Fourier Transform Infrared Spectroscopy; C8:0-C24:0 saturated octanoic-tetracosanoic fatty acids; signifies 
total carbon number; C8di, C9di: octanedioic and nonanedioic acids; $\Delta \mathrm{v}$ : the difference between peak maxima between antisymmetric and symmetric carboxylate absorptions in metal soaps; sFA: saturated fatty acids.

\section{References}

1. Mills, J.S. The Organic Chemistry of Museum Objects, 2nd ed.; Butterworth-Heinemann: Oxford, UK, 2003.

2. Mills, J.S. The Gas Chromatographic Examination of Paint Media. Part, I. Fatty Acid Composition and Identification of Dried Oil Films. Stud. Conserv. 1966, 11, 92-107. [CrossRef]

3. Mills, J.S.; White, R. The gas-chromatographic examination of paint media. Part II. Some examples of medium identification in paintings by fatty acid analysis. Stud. Conserv. 1972, 17, 721-728. [CrossRef]

4. Nawar, W.W. Thermal degradation of lipids. J. Agric. Food Chem. 1969, 17, 18-21. [CrossRef]

5. Casadio, F.; Keune, K.; Noble, P.; Van Loon, A.; Hendriks, E.; Centeno, S.A.; Osmond, G. Metal Soaps in Art; Springer International Publishing: Cham, Switzerland, 2019.

6. Hermans, J.J. Metal Soaps in Oil Paint: Structure, Mechanisms and Dynamics; University of Amsterdam: Amsterdam, The Netherlands, 2017.

7. Keune, K.; Boon, J.J. Analytical Imaging Studies of Cross-Sections of Paintings Affected by Lead Soap Aggregate Formation. Stud. Conserv. 2007, 52, 161-176. [CrossRef]

8. Vichi, A.; Eliazyan, G.; Kazarian, S.G. Study of the Degradation and Conservation of Historical Leather Book Covers with Macro Attenuated Total Reflection-Fourier Transform Infrared Spectroscopic Imaging. ACS Omega 2018, 3, 7150-7157. [CrossRef]

9. Koupadi, K.; Boyatzis, S.C.; Roumpou, M. Organic remains in archaeological objects: Investigating their surviving profile in early Christian Egyptian vessels with Fou-rier Transform Infrared Spectroscopy and Gas Chromatog-raphy-Mass Spectrometry. Heritage 2021. (submitted).

10. Regert, M.; Bland, H.A.; Dudd, S.N.; Bergen, P.V.; Evershed, R.P. Free and bound fatty acid oxidation products in archaeological ceramic vessels. Proc. R. Soc. B Biol. Sci. 1998, 265, 2027-2032. [CrossRef]

11. McGovern, P.E.; Hall, G.R. Charting a Future Course for Organic Residue Analysis in Archaeology. J. Archaeol. Method Theory 2016, 23, 592-622. [CrossRef]

12. Historic England. Organic Residue Analysis and Archaeology; Supporting Information; Historic England: London, UK, 2017; Volume 32.

13. Orna, M.V.; Lambert, J.B. New directions in archaeological chemistry. In Archaeological Chemistry; American Chemical Society: Washingtom, DC, USA, 1996; pp. 1-9.

14. Price, T.D.; Burton, J.H. Archaeological Chemistry. In An Introduction to Archaeological Chemistry; Springer: New York, NY, USA, 2011; pp. 1-24.

15. Lambert, J.B. Traces of the Past: Unraveling the Secrets of Archaeology Through Chemistry, 1st ed.; Perseus Books: Boston, MA, USA, 1998.

16. Evershed, R.P.; Payne, S.; Sherratt, A.G.; Copley, M.S.; Coolidge, J.; Urem-Kotsu, D.; Burton, M.M. Earliest date for milk use in the Near East and southeastern Europe linked to cattle herding. Nature 2008, 455, 528-531. [CrossRef]

17. Maniatis, Y.; Tsirtsoni, Z. Characterization of a black residue in a decorated Neolithic pot from Dikili Tash, Greece: An unexpected result. Archaeometry 2002, 44, 229-239. [CrossRef]

18. Spangenberg, J.E.; Jacomet, S.; Schibler, J. Chemical analyses of organic residues in archaeological pottery from Arbon Bleiche 3, Switzerland-Evidence for dairying in the late Neolithic. J. Archaeol. Sci. 2006, 33, 1-13. [CrossRef]

19. Maritan, L.; Nodari, L.; Mazzoli, C.; Milanob, A.; Russob, U. Influence of firing conditions on ceramic products: Experimental study on clay rich in organic matter. Appl. Clay Sci. 2006, 31, 1-15. [CrossRef]

20. Mitkidou, S.; Dimitrakoudi, E.; Urem-Kotsou, D.; Papadopoulou, D.; Kotsakis, K.; Stratis, J.A.; Stephanidou-Stephanatou, I. Organic residue analysis of Neolithic pottery from North Greece. Microchim. Acta 2008, 160, 493-498. [CrossRef]

21. Raven, A.M.; van Bergen, P.F.; Stott, A.W.; Dudd, S.N.; Evershed, R.P. Formation of long-chain ketones in archaeological pottery vessels by pyrolysis of acyl lipids. J. Anal. Appl. Pyrolysis 1997, 40-41, 267-285. [CrossRef]

22. Suryanarayan, A.; Cubas, M.; Craig, O.E.; Herone, C.P.; Shinde, V.S.; Singh, R.N.; O'Connell, T.C.; Petrie, C.A. Lipid residues in pottery from the Indus Civilisation in northwest India. J. Archaeol. Sci. 2021, 125, 105291. [CrossRef] [PubMed]

23. Lettieri, M. Infrared spectroscopic characterization of residues on archaeological pottery through different spectra acquisition modes. Vib. Spectrosc. 2015, 76, 48-54. [CrossRef]

24. Shillito, L.M.; Almond, M.J.; Wicks, K.; Marshall, L.-J.R.; Matthews, W. The use of FT-IR as a screening technique for organic residue analysis of archaeological samples. Spectrochim. Acta Part A Mol. Biomol. Spectrosc. 2009, 72, 120-125. [CrossRef]

25. McGovern, P.E.; Glusker, D.L.; Exner, L.J.; Voigt, M.M. Neolithic resinated wine. Nature 1996, 381, 480-481. [CrossRef]

26. Stern, B.; Heron, C.; Tellefsen, T.; Serpico, M. New investigations into the Uluburun resin cargo. J. Archaeol. Sci. 2008, 35, 2188-2203. [CrossRef]

27. Hammann, S.; Scurr, D.J.; Alexander, M.R.; Cramp, L.J.E. Mechanisms of lipid preservation in archaeological clay ceramics revealed by mass spectrometry imaging. Proc. Natl. Acad. Sci. USA 2020, 117, 14688-14693. [CrossRef] 
28. Regert, M. Analytical strategies for discriminating archeological fatty substances from animal origin. Mass Spectrom. Rev. 2011, 30, 177-220. [CrossRef] [PubMed]

29. Mottram, H.R.; Evershed, R.P. Structure Analysis of Triacylglycerol Positional Isomers Using Atmospheric Pressure Chemical Ionisation Mass Spectrometry. Tetrahedron Lett. 1996, 37, 8593-8596. [CrossRef]

30. Mottram, H.; Dudd, S.; Lawrence, G.; Stott, A.W.; Evershed, R.P. New chromatographic, mass spectrometric and stable isotope approaches to the classification of degraded animal fats preserved in archaeological pottery. J. Chromatogr. A 1999, 833, $209-221$. [CrossRef]

31. Heron, C.; Evershed, R.P. The Analysis of Organic Residues and the Study of Pottery Use The Analysis of Organic Residues and the Study of Pottery Use. Archaeol. Method Theory 1993, 5, 247-284.

32. McGovern, P.; Jalabadze, M.; Batiuk, S.; Callahan, M.P.; Smith, K.E.; Hall, G.R.; Kvavadze, E.; Maghradze, D.; Rusishvili, N.; Bouby, L.; et al. Early Neolithic wine of Georgia in the South Caucasus. Proc. Natl. Acad. Sci. USA 2017, 114, E10309-E10318. [CrossRef]

33. Izzo, F.C.; Zendri, E.; Bernardi, A.; Balliana, E.; Sgobbi, M. The study of pitch via gas chromatography-mass spectrometry and Fourier-transformed infrared spectroscopy: The case of the Roman amphoras from Monte Poro, Calabria (Italy). J. Archaeol. Sci. 2013, 40, 595-600. [CrossRef]

34. Regert, M.; Garnier, N.; Decavallas, O.; Cren-Olivé, C.; Rolando, C. Structural characterization of lipid constituents from natural substances preserved in archaeological environments. Meas. Sci. Technol. 2003, 14, 1620-1630. [CrossRef]

35. Craig, O.E.; Steele, V.J.; Fischer, A.; Hartz, S.; Andersen, S.H.; Donohoe, P.; Glykou, A.; Saul, H.; Jones, D.M.; Koch, E.; et al. Ancient lipids reveal continuity in culinary practices across the transition to agriculture in Northern Europe. Proc. Natl. Acad. Sci. USA 2011, 108, 17910-17915. [CrossRef]

36. Roffet-Salque, M.; Dunne, J.; Altoft, D.T.; Casanova, E.; Cramp, L.J.E.; Smyth, J.; Whelton, H.L.; Evershed, R.P. From the inside out: Upscaling organic residue analyses of archaeological ceramics. J. Archaeol. Sci. Rep. 2017, 16, 627-640. [CrossRef]

37. Gregg, M.W.; Slater, G.F. A new method for extraction, isolation and transesterification of free fatty acids from archaeological pottery. Archaeometry 2010, 52, 833-854. [CrossRef]

38. Šoberl, L.; Žibrat Gašparič, A.; Budja, M.; Evershed, R.P. Early herding practices revealed through organic residue analysis of pottery from the early Neolithic rock shelter of Mala Triglavca, Slovenia. Doc. Praehist. 2008, 35, 253-260. [CrossRef]

39. McGovern, P.E.; Glusker, D.L.; Moreau, R.A.; Nuñez, A.; Beck, C.W.; Simpson, E.; Butrym, E.D.; Exner, L.J.; Stout, E.C. A funerary feast fit for King Midas. Nature 1999, 402, 863-864. [CrossRef]

40. Boyatzis, S.C.; Kotzamani, D.; Phoca, A.; Karydi, G.M.Z.A.V.K. Characterization of Organic Remains Found in Copper Alloy Vessels of the Benaki Museum Collection with Fourier Transform Mid-Infrared Spectroscopy. In Proceedings of the 3rd ARCH_RNT, Kalamata, Greece, 3-5 October 2012; Zacharias, N., Ed.; University of the Peloponnese: Tripoli, Greece, 2014.

41. Evershed, R.P.; Dudd, S.N.; Copley, M.S.; Berstan, B.; Stott, A.W.; Mottram, H.; Buckley, S.A.; Crossman, Z. Chemistry of archaeological animal fats. Acc. Chem. Res. 2002, 35, 660-668. [CrossRef] [PubMed]

42. Harper, C.S.; Macdonald, F.V.; Braun, K.L. Lipid Residue Analysis of Archaeological Pottery: An Introductory Laboratory Experiment in Archaeological Chemistry. J. Chem. Educ. 2017, 94, 1309-1313. [CrossRef]

43. Heron, C.; Stacey, R. Archaeology: Uses of Chromatography in; Academic Press: Cambridge, MA, USA, 2000; pp. $2083-2089$.

44. Stern, B.; Heron, C.; Serpico, M.; Bourriau, J. A comparison of methods for establishing fatty acid concentration gradients across potsherds: A case study using Late Bronze Age Canaanite amphorae. Archaeometry 2000, 42, 399-414. [CrossRef]

45. Pitonzo, R.; Armetta, F.; Saladino, M.L.; Oliveri, F.; Tusa, S.; Caponetti, E. Application of Gas Chromatography coupled with Mass Spectroscopy (GC/MS) to the analysis of archaeological ceramic amphorae belonging to the Carthaginian fleet that was defeated in the Egadi battle (241 B.C.). Acta IMEKO 2017, 6, 67-70. [CrossRef]

46. Sciutto, G.; Oliveri, P.; Prati, S.; Quaranta, M.; Lanteri, S.; Mazzeo, R. Analysis of paint cross-sections: A combined multivariate approach for the interpretation of $\mu$ ATR-FTIR hyperspectral data arrays. Anal. Bioanal. Chem. 2013, 405, 625-633. [CrossRef]

47. Mazzeo, R.; Prati, S.; Quaranta, M.; Joseph, E.; Kendix, E.; Galeotti, M. Attenuated total reflection micro FTIR characterisation of pigment-binder interaction in reconstructed paint films. Anal. Bioanal. Chem. 2008, 392, 65-76. [CrossRef]

48. Spring, M.; Ricci, C.; Peggie, D.A.; Kazarian, S.G. ATR-FTIR imaging for the analysis of organic materials in paint cross sections: Case studies on paint samples from the National Gallery, London. Anal. Bioanal. Chem. 2008, 392, 37-45. [CrossRef]

49. Bonaduce, I.; Ribechini, E.; Modugno, F.; Colombini, M.P. Analytical approaches based on gas chromatography mass spectrometry (GC/MS) to study organic materials in artworks and archaeological objects. Top Curr. Chem. 2016, 374, 1-37. [CrossRef] [PubMed]

50. Stuart, B.H. Infrared Spectroscopy: Fundamentals and Applications; John Wiley \& Sons, Ltd.: Chichester, UK, 2004.

51. Griffiths, P.R.; Haseth, J.A. Fourier Transform Infrared Spectrometry, 2nd ed.; Wiley-Interscience: Hoboken, NJ, USA, 2007.

52. Griffiths, P.R. Introduction to Vibrational Spectroscopy. In Handbook of Vibrational Spectroscopy; John Wiley \& Sons Inc.: Hoboken, NJ, USA, 2007. [CrossRef]

53. Derrick, M.R.; Stulik, D.; Landry, J.M. Infrared Spectroscopy in Conservation Science; Getty Conservation Institute: Los Angeles, CA, USA, 1999.

54. Stuart, B.H. Analytical Techniques in Materials Conservation; John Wiley \& Sons: Chichester, UK, 2007.

55. Meilunas, R.J.; Bentsen, J.G.; Steinberg, A. Analysis of aged paint binders by ftir spectroscopy. Stud. Conserv. 1990, 35, 33-51. [CrossRef] 
56. Coates, J. Interpretation of Infrared Spectra, A Practical Approach. In Encyclopedia of Analytical Chemistry; John Wiley \& Sons Ltd.: Chichester, UK, 2006; pp. 10815-10837.

57. Bellamy, L.J. The Infra-Red Spectra of Complex Molecules; Springer: Dordrecht, The Netherlands, 1975.

58. Shurvell, H.F. Spectra-Structure Correlations in the Mid- and Far-Infrared. In Handbook of Vibrational Spectroscopy; Chalmers, J.M., Ed.; John Wiley \& Sons, Ltd.: Chichester, UK, 2006.

59. Mayo, D.; Miller, F.; Hannah, R. Course Notes on the Interpretation of Infrared and Raman Spectra; John Wiley \& Sons Inc.: Hoboken, NJ, USA, 2004.

60. Larkin, P. Infrared and Raman Spectroscopy: Principles and Spectral Interpretation; Elsevier: Amsterdam, The Netherlands, 2011.

61. Szymanski, H.A. Interpreted Infrared Spectra_Volume 1-Springer US (1964); Plenum Press: New York, NY, USA, 1981.

62. Silverwood, I.P.; Keyworth, C.W.; Brown, N.J.; Shaffer, M.S.P.; Williams, C.K.; Hellgardt, K.; Kelsall, G.H.; Kazarian, S.G. An attenuated total reflection fourier transform infrared (ATR FT-IR) spectroscopic study of gas adsorption on colloidal stearatecapped ZnO catalyst substrate. Appl. Spectrosc. 2014, 68, 88-94. [CrossRef] [PubMed]

63. Andrew Chan, K.L.; Kazarian, S.G. Attenuated total reflection Fourier-transform infrared (ATR-FTIR) imaging of tissues and live cells. Chem. Soc. Rev. 2016, 45, 1850-1864. [CrossRef]

64. Umemura, J. Reflection-Absorption Spectroscopy of Thin Films on Metallic Substrates. In Handbook of Vibrational Spectroscopy; Chalmers, J.M., Ed.; John Wiley \& Sons Ltd.: Chichester, UK, 2006.

65. Claybourn, M. External Reflection Spectroscopy. In Handbook of Vibrational Spectroscopy; Chalmers, J.M., Ed.; John Wiley \& Sons Ltd.: Chichester, UK, 2006.

66. Bitossi, G.; Giorgi, R.; Mauro, M.; Salvadori, B.; Dei, L. Spectroscopic Techniques in Cultural Heritage Conservation: A Survey. Appl. Spectrosc. Rev. 2005, 40, 187-228. [CrossRef]

67. Prati, S.; Sciutto, G.; Bonacini, I.; Mazzeo, R. New Frontiers in Application of FTIR Microscopy for Characterization of Cultural Heritage Materials. Top. Curr. Chem. 2016, 374, 1-32. [CrossRef] [PubMed]

68. Mazzeo, R.; Joseph, E.; Prati, S.; Millemaggi, A. Attenuated Total Reflection-Fourier transform infrared microspectroscopic mapping for the characterisation of paint cross-sections. Anal. Chim. Acta 2007, 599, 107-117. [CrossRef]

69. Van der Weerd, J.; van Loon, A.; Boon, J.J. FTIR Studies of the Effects of Pigments on the Aging of Oil. Stud. Conserv. 2005, 50, 3-22. [CrossRef]

70. Osmond, G.; Boon, J.J.; Puskar, L.; Drennan, J. Metal Stearate Distributions in Modern Artists' Oil Paints: Surface and CrossSectional Investigation of Reference Paint Films Using Conventional and Synchrotron Infrared Microspectroscopy. Appl. Spectrosc. 2012, 66, 1136-1144. [CrossRef]

71. Hermans, J.J.; Keune, K.; van Loon, A.; Stols-Witlox, M.J.N.; Corkery, R.W.; Iedema, P.D. The synthesis of new types of lead and zinc soaps: A source of information for the study of oil paint degradation. In Proceedings of the ICOM-CC 17th Triennial Conference, Melbourne, Australia, 15-19 September 2014; p. 1603.

72. Hermans, J.J.; Keune, K.; Van Loon, A.; Corkery, R.W.; Iedema, P.D. Ionomer-like structure in mature oil paint binding media. RSC Adv. 2016, 6, 93363-93369. [CrossRef]

73. Hermans, J.J.; Keune, K.; Van Loon, A.; Iedema, P.D. An infrared spectroscopic study of the nature of zinc carboxylates in oil paintings. J. Anal. At. Spectrom. 2015, 30, 1600-1608. [CrossRef]

74. Casadio, F.; Bellot-Gurlet, L.; Paris, C. Factors Affecting the Reactivity of Zinc Oxide with Different Drying Oils: A Vibrational Spectroscopy Study. In Metal Soaps in Art; Springer Publishing: Cham, Switzerland, 2019; pp. 153-170.

75. Banti, D.; La Nasa, J.; Tenorio, A.L.; Modugno, F.; Berg, K.J.V.A.; Lee, J.; Ormsby, B.; Burnstock, A.; Bonaduce, I. A molecular study of modern oil paintings: Investigating the role of dicarboxylic acids in the water sensitivity of modern oil paints. RSC Adv. 2018, 8, 6001-6012. [CrossRef]

76. Ma, X.; Beltran, V.; Ramer, G.; Georges, P.; Dilworthy, P.; Tyler, M.; Andrea, C.; Barbara, B. Revealing the Distribution of Metal Carboxylates in Oil Paint from the Micro- to Nanoscale. Angew. Chem. Int. Ed. 2019, 58, 11652-11656. [CrossRef]

77. Hermans, J.J.; Keune, K.; Van Loon, A.; Iedema, P.D. The crystallization of metal soaps and fatty acids in oil paint model systems. Phys. Chem. Chem. Phys. 2016, 18, 10896-10905. [CrossRef] [PubMed]

78. Robinet, L.; Corbeil, M.C. The characterization of metal soaps. Stud. Conserv. 2003, 48, 23-40. [CrossRef]

79. Oudemans, T.F.M.; Boon, J.J.; Botto, R.E. FTIR and solid-state 13C CP/MAS NMR spectroscopy of charred and non-charred solid organic residues preserved in roman iron age vessels from the Netherlands. Archaeometry 2007, 49, 571-294. [CrossRef]

80. McGovern, P.E. Uncorking the Past. The Quest for Wine, Beer, and Other Alcoholic Beverages; University of California Press: Berkeley, CA, USA, 2009.

81. Thickett, D.; Pretzel, B. Micro-spectroscopy: A powerful tool to understand deterioration. e-Preserv. Sci. 2010, 7, 158-164.

82. Plater, M.J.; De Silva, B.; Gelbrich, T.; Hursthouse, M.; Higgitt, C.; Saunders, D. The characterisation of lead fatty acid soaps in "protrusions" in aged traditional oil paint. Polyhedron 2003, 22, 3171-3179. [CrossRef]

83. Hermans, J.J.; Keune, K.; van Loon, A.; Corkery, R.W.; Iedema, P.D. The molecular structure of three types of long-chain zinc(II) alkanoates for the study of oil paint degradation. Polyhedron 2014, 81, 335-340. [CrossRef]

84. Otero, V.; Sanches, D.; Montagner, C.; Vilarigues, M.; Carlyle, L.; Lopes, J.A.; Melo, M.J. Supporting Information: Characterisation of metal carboxylates by Raman and infrared spectroscopy in works of art. J. Raman. Spectrosc. 2014, 45, 1197-1206. [CrossRef]

85. Gönen, M.; Öztürk, S.; Balköse, D.; Okur, S.; Ülkü, S. Preparation and characterization of calcium stearate powders and films prepared by precipitation and Langmuir-Blodgett techniques. Ind. Eng. Chem. Res. 2010, 49, 1732-1736. [CrossRef] 
86. Pauling, L.; Brockway, L.O. The Structure of the Carboxyl Group: I. The Investigation of Formic Acid by the Diffraction of Electrons. Proc. Natl. Acad. Sci. USA 1934, 20, 336-340. [CrossRef]

87. Kishida, S.; Nakamoto, K. Normal coordinate analyses of hydrogen-bonded compounds. II. Dimeric formic acid and acetic acid. J. Chem. Phys. 1964, 41, 1558-1563. [CrossRef]

88. Witkowski, A. Infrared Spectra of the Hydrogen-Bonded Carboxylic Acids. J. Chem. Phys. 1967, 47, 3645-3648. [CrossRef]

89. Kaneko, F.; Tashiro, K.; Kobayashi, M. Polymorphic transformations during crystallization processes of fatty acids studied with FT-IR spectroscopy. J. Cryst. Growth 1999, 198-199, 1352-1359. [CrossRef]

90. Kaneko, F.; Ishikawa, E.; Kobayashi, M.; Suzuki, M. Structural study on polymorphism of long-chain dicarboxylic acids using oblique transmission method for micro FT-IR spectrometers. Spectrochim. Acta Part A Mol. Biomol. Spectrosc. 2004, 60, 9-18. [CrossRef]

91. Thalladi, V.R.; Nüsse, M.; Boese, R. The melting point alternation in $\alpha, \omega$-alkanedicarboxylic acids. J. Am. Chem. Soc. 2000, 122, 9227-9236. [CrossRef]

92. Badger, R.M.; Bauer, S.H. Spectroscopic studies of the hydrogen bond I. A photometric investigation of the association equilibrium in the vapor of acetic acid. J. Chem. Phys. 1937, 5, 605-608. [CrossRef]

93. Badger, R.M.; Bauer, S.H. Spectroscopic studies of the hydrogen bond. II. The shift of the O-H vibrational frequency in the formation of the hydrogen bond. J. Chem. Phys. 1937, 5, 839-851. [CrossRef]

94. Fox, J.J.; Martin, A.E. Investigations of infra-red spectra-absorption of some hydroxy compounds in the region of $3 \mu$. Proc. R. Soc. Lond. Ser. A Math. Phys. Sci. 1937, 162, 419-441. [CrossRef]

95. Buswell, A.M.; Rodebush, W.H.; Roy, M.F. Infrared Absorption Studies. V. Association in the Carboxylic Acids. J. Am. Chem. Soc. 1938, 60, 2239-2244. [CrossRef]

96. Davies, M.M.; Sutherland, G.B.B.M. Hydroxyl Frequency in Carboxylic Acids. Nature 1938, 141, 372-373. [CrossRef]

97. Cannon, C.G. The nature of hydrogen bonding. Spectrochim. Acta 1958, 10, 341-368. [CrossRef]

98. Hadži, D. Hydrogen Bonding. In Proceedings of the Symposium on Hydrogen Bonding, Ljubljana, Slovenia, 29 July-3 August 1957; Pergamon Press: Oxford, UK, 1959.

99. Nakamoto, K.; Margoshes, M.; Rundle, R. E Stretching Frequencies as a Function of Distances in Hydrogen Bonds. J. Am. Chem. Soc. 1955, 77, 6480-6486. [CrossRef]

100. Hadzi, D.; Sheppard, N. The infra-red absorption bands associated with the COOH and COOD groups in dimeric carboxylic acids. I. The region from 1500 to $500 \mathrm{~cm}^{-1}$. Proc. R. Soc. Lond. Ser. A Math. Phys. Sci. 1953, 216, 247-266. [CrossRef]

101. Bratož, S.; Hadži, D.; Sheppard, N. The infra-red absorption bands associated with the COOH and COOD groups in dimeric carboxylic acid-II. The region from 3700 to $1500 \mathrm{~cm}^{-1}$. Spectrochim. Acta 1956, 8, 249-261. [CrossRef]

102. Grabowski, S.J. Hydrogen Bonding - New Insights, 1st ed.; Springer: Dordrecht, The Netherlands, 2006.

103. Bezrodna, T. Temperature dynamics of dimer formation in behenic acid: FT-IR spectroscopic study. J. Mol. Struct. 2013, 1040, 112-116. [CrossRef]

104. Li, Y.-M.; Sun, S.-Q.; Zhou, Q.; Qin, Z.; Tao, J.-X.; Wang, J.; Fang, X. Identification of American ginseng from different regions using FT-IR and two-dimensional correlation IR spectroscopy. Vib. Spectrosc. 2004, 36, 227-232. [CrossRef]

105. Silva, L.F.; Andrade-Filho, T.; Freire, P.T.C. Polarized Raman and Infrared Spectroscopy and ab Initio Calculation of Palmitic and Stearic Acids in the Bm and C Forms. J. Phys. Chem. A 2004, 121, 4830-4842. [CrossRef]

106. Meiklejohn, R.A.; Meyer, R.J.; Aronovic, S.M.; Schuette, H.A.; Meloche, V.W. Characterization of Long-Chain Fatty Acids by Infrared Spectroscopy. Anal. Chem. 1957, 29, 329-334. [CrossRef]

107. De Ruig, W.G. Infrared Spectra of Monoacid Triglycerides with Some Applications to Fat Analysis; Center for Agricultural Publishing and Documentation: Wageningen, The Netherlands, 1971.

108. Corish, P.J.; Chapman, D. The infrared spectra of some monocarboxylic acids. J. Chem. Soc. 1957, 18, 1746. [CrossRef]

109. Chapman, D. Infrared spectroscopy of lipids. J. Am. Oil Chem. Soc. 1965, 42, 353-371. [CrossRef]

110. Sinclair, R.G.; McKay, A.F.; Jones, R.N. The Infrared Absorption Spectra of Saturated Fatty Acids and Esters. J. Am. Chem. Soc. 1952, 74, 2570-2575. [CrossRef]

111. Comí, M.; Fernández, M.; Santamaría, A.; Lligadas, G.; Ronda, J.C.; Galià, M.; Cadiz, V. Carboxylic Acid Ionic Modification of Castor-Oil-Based Polyurethanes Bearing Amine Groups: Chemically Tunable Physical Properties and Recyclability. Macromol. Chem. Phys. 2017, 218, 1700379. [CrossRef]

112. Cheng, Q.; Cao, Y.; Yang, L.; Zhang, P.-P.; Wang, K.; Wang, H.-J. Synthesis of titania microspheres with hierarchical structures and high photocatalytic activity by using nonanoic acid as the structure-directing agent. Mater. Lett. 2011, 65, 2833-2835. [CrossRef]

113. Ali, H.; Ghareeb, M.M.; Al-remawi, M.; Al-akayleh, F.T. New insight into single phase formation of capric acid/menthol eutectic mixtures by Fourier-transform infrared spectroscopy and differential scanning calorimetry. Trop. J. Pharm. Res. 2020, 19, 361-369. [CrossRef]

114. Roy, R.S. Spectroscopic studies of long chain fatty acids. Pyridine-Fatty acid—Carbon tetrachloride system. Spectrochim. Acta 1966, 22, 1877-1887. [CrossRef]

115. Suzuki, M.; Shimanouchi, T. Infrared and Raman spectra of adipic acid crystal. J. Mol. Spectrosci. 1969, 29, 415-425. [CrossRef]

116. Mikawa, Y.; Brasch, J.W.; Jakobsen, R.J. Polarized ir spectra of single crystals of propanoic acid. J. Mol. Struct. 1968, 3, 103-117. [CrossRef]

117. Lide, D.R. Handbook of Chemistry and Physics, 87th ed.; CRC: Boca Raton, FL, USA, 2006. 
118. Zerbi, G.; Conti, G.; Minoni, G.; Pison, S.; Bigotto, A. Premelting phenomena in fatty acids: An infrared and Raman study. J. Phys. Chem. 1987, 91, 2386-2393. [CrossRef]

119. Conti, G.; Minoni, G.; Zerbi, G. E $\rightarrow$ C phase transition in fatty acids: A spectroscopic study. J. Mol. Struct. 1984, 118, 237-243. [CrossRef]

120. Flett, M.S.C. The characteristic infra-red frequencies of the carboxylic acid group. J. Chem. Soc. 1951, 41, 962. [CrossRef]

121. Ren, Z.; Ma, D.; Wang, Y.; Zhao, G. Molecular structure and hydrogen bonds in solid dimethylol propionic acid (DMPA). Spectrochim. Acta Part A Mol. Biomol. Spectrosc. 2003, 59, 2713-2722. [CrossRef]

122. Zhu, J.; Ren, Z.; Zhang, G.; Guo, X.; Ma, M. Comparative study of the H-bond and FTIR spectra between 2,2-hydroxymethyl propionic acid and 2,2-hydroxymethyl butanoic acid. Spectrochim. Acta Part A Mol. Biomol. Spectrosc. 2006, 63, 449-453. [CrossRef]

123. Pauling, L. The Nature of the Chemical Bond and the Structure of Molecules and Crystals: An Introduction to Modern Structural Chemistry, 3rd ed.; Cornell University Press: Ithaca, NY, USA, 1960.

124. Li, H.W.; Strauss, H.L.; Snyder, R.G. Differences in the IR methylene rocking bands between the crystalline fatty acids and n-alkanes: Frequencies, intensities, and correlation splitting. J. Phys. Chem. A 2004, 108, 6629-6642. [CrossRef]

125. Lewis, R.N.A.H.; McElhaney, R.N. Vibrational Spectroscopy of Lipids. In Handbook of Vibrational Spectroscopy; Griffiths, P.R., Ed.; John Wiley \& Sons Ltd.: Chichester, UK, 2006.

126. Jones, R.N. The Effects of Chain Length on the Infrared Spectra of Fatty Acids and Methyl Esters. Can. J. Chem. 1962, 40, 321-333. [CrossRef]

127. Lambert, J.B.; Shurvell, H.F.; Cooks, R.G. Introduction to Organic Spectroscopy, 1st ed.; Macmillan: New York, NY, USA, 1987.

128. Smith, B.C. Infrared Spectral Interpretation: A Systematic Approach; CRC Press: Boca Raton, FL, USA, 1998.

129. Zbinden, R. Infrared Spectroscopy of High Polymers; Academic Press: New York, NY, USA; London, UK, 1964.

130. Snyder, R.G.; Schachtschneider, J.H. Vibrational analysis of the n-paraffins-I. Assignments of infrared bandsin the spectra of C3H8 through n-C19H40. Spectrochim. Acta 1963, 19, 85-116. [CrossRef]

131. Jones, R.N.; McKay, A.F.; Sinclair, R.G. Band Progressions in the Infrared Spectra of Fatty Acids and Related Compounds. J. Am. Chem. Soc. 1952, 74, 2575-2578. [CrossRef]

132. Boyatzis, S.; Douvas, A.M.; Argyropoulos, V.; Siatou, A.; Vlachopoulou, M. Characterization of a water-dispersible metal protective coating with fourier transform infrared spectroscopy, modulated differential scanning calorimetry, and ellipsometry. Appl. Spectrosc. 2012, 66, 580-590. [CrossRef]

133. Kirby, E.M.; Evans-Vader, M.J.; Brown, M.A. Determination of the length of polymethylene chains in salts of saturated and unsaturated fatty acids by infrared spectroscopy. J. Am. Oil Chem. Soc. 1965, 42, 437-446. [CrossRef]

134. Chapman, D. The $720 \mathrm{~cm}-1$ band in the infrared spectra of crystalline long-chain compounds. J. Chem. Soc. 1957, $4489-4491$. [CrossRef]

135. Ross, R.A.; Takacs, A. Heterogeneous Reactions of Aluminum and Copper Surfaces with Stearic Acid. Ind. Eng. Chem. Prod. Res. Dev. 1983, 22, 280-286. [CrossRef]

136. Ross, R.A.; Takacs, A.M. Surface reactions of ethyl stearate and stearic acid with zinc, manganese and their oxides. Surf. Technol. 1984, 21, 361-377. [CrossRef]

137. Dou, Q.; Ng, K.M. Synthesis of various metal stearates and the corresponding monodisperse metal oxide nanoparticles. Powder Technol. 2016, 301, 949-958. [CrossRef]

138. Corkery, R.W. Artificial Biomineralisation and Metallic Soaps; Australian National University: Canberra, Australia, 1998.

139. Nora, A.; Szczepanek, A.; Koenen, G. Metallic soaps. In Ullmann's Encyclopedia of Industrial Chemistry; Lauro, M.F., Ed.; Wiley-VCH: Weinheim, Germany, 2005; pp. 329-332.

140. Osmond, G. Zinc Soaps: An Overview of Zinc Oxide Reactivity and Consequences of Soap Formation in Oil-Based Paintings. In Metal Soaps in Art; Casadio, F., Noble, P., Hendricks, E., Eds.; Springer: Cham, Switzerland, 2019; pp. 25-46.

141. Noble, P. A Brief History of Metal Soaps in Paintings from a Conservation Perspective. In Metal Soaps in Art; Casadio, F., Noble, P., Hendricks, E., Eds.; Springer: Cham, Switzerland, 2019; pp. 1-22.

142. Raven, L.E.; Bisschoff, M.; Leeuwestein, M.; Geldof, M.; Hermans, J.J.; Stols-Witlox, M.; Keune, K. Delamination Due to Zinc Soap Formation in an Oil Painting by Piet Mondrian (1872-1944). In Metal Soaps in Art; Casadio, F., Noble, P., Hendricks, E., Eds.; Springer: Cham, Switzerland, 2019; pp. 343-358.

143. Thomas, M.M.; Clouse, J.A.; Longo, J.M. Adsorption of organic compounds on carbonate minerals. 1. Model compounds and their influence on mineral wettability. Chem. Geol. 1993, 109, 201-213. [CrossRef]

144. Frye, G.C.; Thomas, M.M. Adsorption of organic compounds on carbonate minerals. 2. Extraction of carboxylic acids from recent and ancient carbonates. Chem. Geol. 1993, 109, 215-226. [CrossRef]

145. Boon, J.J.; Hoogland, F.; Keune, K.; Parkin, H.M. Chemical processes in aged oil paints affecting metal soap migration and aggregation. In Proceedings of the AIC's 34th Annual Meeting, Providence, RI, USA, 16-19 June 2006; Volume 19, pp. 16-23.

146. La Nasa, J.; Modugno, F.; Aloisi, M.; Lluveras-Tenorio, A.; Bonaduce, I. Development of a GC/MS method for the qualitative and quantitative analysis of mixtures of free fatty acids and metal soaps in paint samples. Anal. Chim. Acta 2018, 1001. [CrossRef]

147. Hermans, J.; Helwig, K. The Identification of Multiple Crystalline Zinc Soap Structures Using Infrared Spectroscopy. Appl. Spectrosc. 2020, 74, 1505-1514. [CrossRef] [PubMed]

148. Nakamoto, K. Infrared and Raman Spectra of Inorganic and Coordination Compounds, Part B, Applications in Coordination, Organometallic, and Bioinorganic Chemistry, 6th ed.; John Wiley \& Sons: Hoboken, NJ, USA, 2009. 
149. Palacios-beas, E. Infrared spectroscopy of metal carboxylates: II. Analysis of Fe (III), Ni and Zn carboxylate solutions. Hydrometallurgy 2004, 72, 139-148. [CrossRef]

150. Deacon, G.B.; Phillips, R.J. Relationships between the carbon-oxygen stretching frequencies of carboxylato complexes and the type of carboxylate coordination. Coord. Chem. Rev. 1980, 33, 227-250. [CrossRef]

151. Zeleňák, V.; Vargová, Z.; Györyová, K. Correlation of infrared spectra of zinc(II) carboxylates with their structures. Spectrochim. Acta Part A Mol. Biomol. Spectrosc. 2007, 66, 262-272. [CrossRef]

152. Desseyn, H.O. Vibrational analysis of acid derivatives. In The Chemistry of Acid Derivatives. The Chemistry of Functional Groups; Patai, S., Ed.; John Wiley \& Sons: Chichester, UK, 1992; Volume 2, Supplement B; pp. 271-304.

153. Lynch, M.L.; Pan, Y.; Laughlin, R.G. Spectroscopic and Thermal Characterization of 1:2 Sodium Soap/Fatty Acid Acid-Soap Crystals. J. Phys. Chem. 1996, 100, 357-361. [CrossRef]

154. Lu, Y.; Miller, J.D. Carboxyl stretching vibrations of spontaneously adsorbed and LB-transferred calcium carboxylates as determined by FTIR internal reflection spectroscopy. J. Colloid Interface Sci. 2002, 256, 41-52. [CrossRef]

155. Hermans, J.J.; Baij, L.; Koenis, M.; Keune, K.; Iedema, P.D. 2D-IR spectroscopy for oil paint conservation: Elucidating the water-sensitive structure of zinc carboxylate clusters in ionomers. Sci. Adv. 2019, 5, 1-10. [CrossRef] [PubMed]

156. Catalano, J.; Murphy, A.; Yao, Y.; Yap, G.P.A.; Zumbulyadis, N.; Centeno, S.; Dybowski, C. Coordination geometry of lead carboxylates-Spectroscopic and crystallographic evidence. Dalton Trans. 2015, 44, 2340-2347. [CrossRef]

157. Cotton, F.A. Modern Coordination Chemistry; Wiley-Interscience: New York, NY, USA, 1960.

158. Nickolov, Z.; Georgiev, G.; Stoilova, D.; Ivanov, I. Raman and IR study of cobalt acetate dihydrate. J. Mol. Struct. 1995, 354, 119-125. [CrossRef]

159. Martínez-Casado, F.J.; Rodríguez-Cheda, J.A.; Ramos-Riesco, M.; Redondo-Yélamos, M.I.; Cucinotta, F.; Fernández-Martínez, A. Physicochemistry of Pure Lead(II) Soaps: Crystal Structures, Solid and Liquid Mesophases, and Glass Phases-Crystallographic, Calorimetric, and Pair Distribution Function Analysis. In Metal Soaps in Art; Springer: Cham, Switzerland, 2019 ; pp. $227-239$.

160. Hermans, J.J.; Keune, K.; Van Loon, A.; Iedema, P.D. Toward a Complete Molecular Model for the Formation of Metal Soaps in Oil Paints. In Metal Soaps in Art; Springer: Cham, Switzerland, 2019; pp. 47-67.

161. Corkery, R.W. Langmuir-Blodgett (L-B) multilayer films. Langmuir 1997, 13, 3591-3594. [CrossRef]

162. Passi, S.; Picardo, M.; De Luca, C.; Luca, C.D.; Nazzaro-Porro, M.; Rossi, L.; Rotilio, G. Saturated dicarboxylic acids as products of unsaturated fatty acid oxidation. Biochim. Biophys. Acta Lipids Lipid Metab. 1993, 1168, 190-198. [CrossRef]

163. Ioakimoglou, E.; Boyatzis, S.; Argitis, P.; Fostiridou, A.; Papapanagiotou, K.; Yannovits, N. Thin-Film Study on the Oxidation of Linseed Oil in the Presence of Selected Copper Pigments. Chem. Mater. 1999, 11, 2013-2022. [CrossRef]

164. Colombini, M.P.; Modugno, F.; Ribechini, E. Organic mass spectrometry in archaeology: Evidence for Brassicaceae seed oil in Egyptian ceramic lamps. J. Mass Spectrom. 2005, 40, 890-898. [CrossRef]

165. Ménager, M.; Azémard, C.; Vieillescazes, C. Study of Egyptian mummification balms by FT-IR spectroscopy and GC-MS. Microchem. J. 2014, 114, 32-41. [CrossRef]

166. Lee, J.; Bonaduce, I.; Modugno, F.; Nasa, J.L.; Ormsby, B.; Berg, K.J.v.d. Scientific investigation into the water sensitivity of twentieth century oil paints. Microchem. J. 2018, 138, 282-295. [CrossRef]

167. Modugno, F.; Di Gianvincenzo, F.; Degano, I.; Werf, I.D.v.d.; Bonaduce, I.; Berg, K.J.v.d. On the influence of relative humidity on the oxidation and hydrolysis of fresh and aged oil paints. Sci. Rep. 2019, 9, 5533. [CrossRef]

168. Colombini, M.P.; Modugno, F.; Giacomelli, M.; Francesconi, S. Characterisation of proteinaceous binders and drying oils in wall painting samples by gas chromatography-mass spectrometry. J. Chromatogr. A 1999, 846, 113-124. [CrossRef]

169. Bonaduce, I.; Carlyle, L.; Colombini, M.P.; Duce, C.; Ferrari, C.; Ribechini, E.; Selleri, P.; Tiné, M.R. New Insights into the Ageing of Linseed Oil Paint Binder: A Qualitative and Quantitative Analytical Study. PLoS ONE 2012, 7, e49333. [CrossRef]

170. Dunitz, J.D.; Robertson, J.M. The crystal and molecular structure of certain dicarboxylic acids. Part, I. Oxalic acid dihydrate. J. Chem. Soc. 1944, 142-148. [CrossRef]

171. Morrison, J.D.; Robertson, J.M. The crystal and molecular structure of certain dicarboxylic acids. Part IV. $\beta$-Succinic acid. J. Chem. Soc. 1949, 980-986. [CrossRef]

172. Morrison, J.D.; Robertson, J.M. The crystal and molecular structure of certain dicarboxylic acids. Part, V. Adipic acid. J. Chem. Soc. 1949, 987-992. [CrossRef]

173. Morrison, J.D.; Robertson, J.M. The crystal and molecular structure of certain dicarboxylic acids. Part VI. Sebacic acid. J. Chem. Soc. 1949, 993-1001. [CrossRef]

174. Susi, H. Infrared spectra of crystalline adipic acid and deuterated analogs. Spectrochim Acta 1956, 15, 1063-1071. [CrossRef]

175. Macgillavry, C.H.; Hoogschagen, G.; Sixma, F.L.J. The crystal structure of glutaric and pimelic acid. Alternation of properties in the series of dicarboxylic acids. Recl. des Trav. Chim. des Pays-Bas 2010, 67, 869-883. [CrossRef]

176. Kshnyakina, S.I.; Puchkovskaya, G.A. Spectroscopic investigations of crystals of the homologous series of dicarboxylic acids. J. Appl. Spectrosc. 1981, 34, 556-561. [CrossRef]

177. Nagakura, M.; Ogawa, Y.; Yoshitomi, K. Infrared Spectroscopic Determination of Alkyd Resin Components. J. Jpn. Soc. Colour Mater. 1968, 41, 542-553. [CrossRef]

178. Mishra, M.K.; Varughese, S.; Ramamurty, U.; Desiraju, G.R. Odd-Even effect in the elastic modulii of $\alpha, \omega$ - alkanedicarboxylic acids. J. Am. Chem. Soc. 2013, 135, 8121-8124. [CrossRef] [PubMed] 
179. Nattkemper, A.; Schleiden, T.; Migliavacca, J.M.; Melin, T. Monitoring Crystallization Kinetics of Azelaic Acid by in situ FTIR Spectroscopy in Three-Phase Systems. Chem. Eng. Technol. 2003, 26, 881-889. [CrossRef]

180. Li, M.; Zhang, J.; Huang, K.; Li, S.; Jiang, J.; Xia, J. Mixed calcium and zinc salts of dicarboxylic acids derived from rosin and dipentene: Preparation and thermal stabilization for PVC. RSC Adv. 2014, 4, 63576-63585. [CrossRef] 